\title{
Alpine Botany \\ GENETIC DIVERSITY IN THE ANDES: VARIATION WITHIN AND BETWEEN THE SOUTH AMERICAN SPECIES OF OREOBOLUS R. Br. (CYPERACEAE) --Manuscript Draft--
}

Manuscript Number:

Full Title:

Article Type:

Corresponding Author:
ALBO-D-16-00069R2

GENETIC DIVERSITY IN THE ANDES: VARIATION WITHIN AND BETWEEN THE SOUTH AMERICAN SPECIES OF OREOBOLUS R. Br. (CYPERACEAE)

Original Article

James Richardson

Universidad Del Rosario

COLOMBIA

Corresponding Author Secondary

Information:

Corresponding Author's Institution:

Universidad Del Rosario

Corresponding Author's Secondary Institution:

First Author:

Maria Camila Gómez-Gutiérrez, PhD

First Author Secondary Information:

Order of Authors:

Maria Camila Gómez-Gutiérrez, PhD

Toby Pennington, PhD

Linda Neaves, $\mathrm{PhD}$

Richard Milne, PhD

Santiago Madriñán, $\mathrm{PhD}$

James Richardson, PhD

Order of Authors Secondary Information:

Funding Information:

School of Biological Sciences Scholarship Dr Maria Camila Gómez-Gutiérrez provided through The University of

Edinburgh

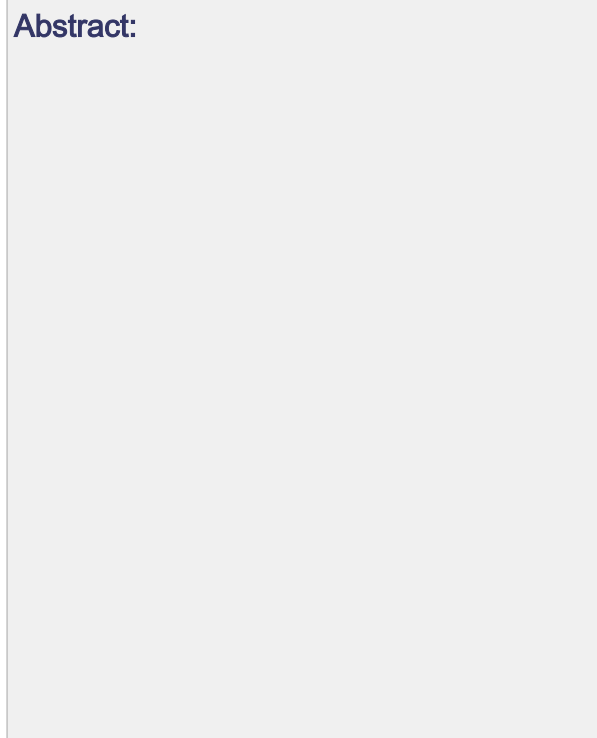

Response to Reviewers:
This study examines genetic relationships among and within the South American species of Oreobolus that span the temperate and tropical Andes hotspots and represent a good case study to investigate diversification in the Páramo. A total of 197 individuals covering the distributional range of most of these species were sequenced for the nuclear ribosomal internal transcribed spacer (ITS) and 118 individuals for three chloroplast DNA regions (trnL-F, trnH-psbA and rpl32-trnL). Haplotype networks and measures of genetic diversity were calculated at different taxonomic and geographic levels. To test for possible geographic structure, a Spatial Analysis of Molecular Variance (SAMOVA) was undertaken and species relationships were recovered using a coalescent-based approach. Results indicate complex relationships among the five South American species of Oreobolus, which are likely to have been confounded by incomplete lineage sorting, though hybridization cannot be completely discarded as an influence on genetic patterns, particularly among the northern populations of $O$. obtusangulus and $\mathrm{O}$. cleefii. We report a case of cryptic speciation in $\mathrm{O}$. obtusangulus where northern and southern populations of morphologically similar individuals are genetically distinct in all analyses. At the population level, the genetic evidence is consistent with contraction and expansion of islands of Páramo vegetation during the climatic fluctuations of the Quaternary, highlighting the role of these processes in shaping modern diversity in that ecosystem. 


\section{GENETIC DIVERSITY IN THE ANDES:}

2 VARIATION WITHIN AND BETWEEN THE

3 SOUTH AMERICAN SPECIES OF OREOBOLUS

4 R. Br. (CYPERACEAE)

5 María Camila Gómez-Gutiérrez ${ }^{1,2}$, R. Toby Pennington ${ }^{1}$, Linda E. Neaves ${ }^{1,3}$, Richard

6 I. Milne ${ }^{2}$, Santiago Madriñán ${ }^{4}$ and James E. Richardson ${ }^{1,5, \dagger}$

$7{ }^{1}$ Tropical Diversity Section, Royal Botanic Garden Edinburgh, 20A Inverleith Row,

8 Edinburgh, EH3 5LR, United Kingdom

$9{ }^{2}$ Institute of Molecular Plant Sciences, School of Biological Sciences, The

10 University of Edinburgh, Daniel Rutherford Building, The King's Buildings,

11 Edinburgh, EH9 3BF, United Kingdom.

$12{ }^{3}$ Australian Centre for Wildlife Genomics, Australian Museum Research Institute,

13 Australian Museum, 1 William Street, Sydney 2010, Australia.

$14{ }^{4}$ Laboratorio de Botánica y Sistemática, Departamento de Ciencias Biológicas,

15 Universidad de los Andes, Carrera 1 No. 18A - 10, Bogotá, Colombia.

$16{ }^{5}$ Programa de Biología, Universidad del Rosario, Carrera 26 No. 63B - 48, Bogotá,

17 Colombia.

$18 \dagger$ Corresponding author, email: jamese.richardson@urosario.edu.co 
20 This study examines genetic relationships among and within the South American

21 species of Oreobolus that span the temperate and tropical Andes hotspots and

22 represent a good case study to investigate diversification in the Páramo. A total of

23197 individuals covering the distributional range of most of these species were

24 sequenced for the nuclear ribosomal internal transcribed spacer (ITS) and 118

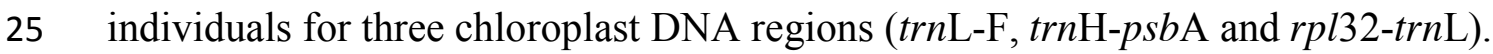

26 Haplotype networks and measures of genetic diversity were calculated at different

27 taxonomic and geographic levels. To test for possible geographic structure, a Spatial

28 Analysis of Molecular Variance (SAMOVA) was undertaken and species

29 relationships were recovered using a coalescent-based approach. Results indicate

30 complex relationships among the five South American species of Oreobolus, which

31 are likely to have been confounded by incomplete lineage sorting, though

32 hybridization cannot be completely discarded as an influence on genetic patterns,

33 particularly among the northern populations of $O$. obtusangulus and $O$.cleefii. We

34 report a case of cryptic speciation in O. obtusangulus where northern and southern

35 populations of morphologically similar individuals are genetically distinct in all

36 analyses. At the population level, the genetic evidence is consistent with contraction

37 and expansion of islands of Páramo vegetation during the climatic fluctuations of the

38 Quaternary, highlighting the role of these processes in shaping modern diversity in 39 that ecosystem. 
41 Biogeography, Andes, species tree, lineage sorting, hybridization, Páramo.

\section{ACKNOWLEDGEMENTS}

43 This work was funded by a School of Biological Sciences Scholarship provided

44 through The University of Edinburgh. We thank the herbaria at Aarhus University,

45 (Denmark), Naturalis (The Netherlands) and Reading University (Great Britain) for

46 making material available for DNA extraction. We also thank three anonymous

47 reviewers for their valuable comments and James Nicholls from The University of

48 Edinburgh for assistance with the *BEAST analysis.

\section{INTRODUCTION}

50 The Páramo is a putatively young ecosystem that appeared following the final uplift

51 of the northern section of the Andes Mountain Range during the Pliocene, c. 5

52 million years ago - Ma (van der Hammen 1974; van der Hammen and Cleef 1986;

53 Hooghiemstra et al. 2006; Graham 2009). It occupies an area of $37500 \mathrm{~km}^{2}$ and is

54 distributed in a series of sky islands with c. 4000 plant species of which $60 \%$ are

55 endemic (Luteyn 1999; Buytaert et al. 2010). It has been proposed that the glacial-

56 interglacial cycles of the Quaternary may have played an important role in shaping

57 Páramo plant populations (van der Hammen 1974; Simpson 1975). The continuous

58 contraction and expansion of altitudinal vegetation belts may have promoted the 
contact of Páramo islands during glacial periods, enabling the migration and

60 exchange of otherwise isolated taxa (van der Hammen and Cleef 1986). Conversely,

61 during interglacial periods, Páramo islands may have been isolated, promoting

62 speciation (van der Hammen and Cleef 1986). Furthermore, previous studies have

63 demonstrated that Páramo lineages have significantly higher speciation rates than

64 any other biodiversity hotspot on Earth and that many speciation events occurred

65 during the Pleistocene (Madriñán et al. 2013). Recent divergence times among

66 Páramo plant lineages might have implications, both at the phenotypic and genotypic

67 level, because morphological diversity and differentiation may not reflect complete

68 genetic divergence between and within closely related taxa (Schaal et al. 1998).

69 The five South American species of the schoenoid sedge Oreobolus R. Br. (O. cleefii

70 L.E. Mora, O. ecuadorensis T. Koyama, O. goeppingeri Suess., O. obtusangulus

71 Gaudich. and O. venezuelensis Steyerm.) are an ideal model system to investigate

72 how recent climatic and/or geological events may have shaped extant populations in

73 the Páramo. Previous studies have supported the monophyly of the South American

74 clade of Oreobolus and dated its divergence to c. 5 Ma, coinciding with the

75 appearance of the Páramo ecosystem (Chacón et al. 2006). The South American

76 clade of Oreobolus is therefore a good exemplar to study Páramo biogeography,

77 including investigating the likely effects of recent climatic events (i.e. glacial cycles

78 of the Quaternary) on the population structure of its species.

79 A handful of genetic studies for similar high-altitude tropical ecosystems in Africa

80 have been published in recent years (Kebede et al. 2007; Assefa et al. 2007; Gizaw et

81 al. 2013; Kadu et al. 2013; Wondimu et al. 2013). However, such studies are almost

82 non-existent for the Páramo flora (Vásquez et al. 2016; Kolář et al. 2016). The aims 
83 of this study are to estimate the species phylogeny of the South American species of

84 Oreobolus and their timing of diversification, to assess genetic structure at the inter-

85 and intra-specific level and to interpret these in the light of Quaternary glacial-

86 interglacial cycles.

\section{METHODS}

$88 \quad$ Study species and sampling

89 The species concepts for Oreobolus that we use here follow the monograph of

90 Seberg (1988) for O. ecuadorensis, O. goeppingeri, O. obtusangulus and $O$.

91 venezuelensis, and of Mora-Osejo (1987) for O. cleefii. These species, with the

92 exception of O. obtusangulus subsp. obtusangulus, are restricted to wet, temperate-

93 like environments in the northern section of the Tropical Andes and in the

94 Talamanca Cordillera in southern Central America, and are found only in the high-

95 altitude Páramo ecosystem (Seberg 1988; Chacón et al. 2006). Oreobolus cleefii is

96 restricted to the Eastern Cordillera and the southern Andean region of Colombia.

97 Oreobolus ecuadorensis is found in southern Colombia, Ecuador and northern Peru.

98 Oreobolus goeppingeri is distributed in the Talamanca Cordillera in southern Central

99 America, Colombia and Ecuador. Oreobolus obtusangulus has two subspecies with a

100 disjunct distribution: subsp. unispicus is distributed in Colombia, Ecuador and

101 northern Peru while subsp. obtusangulus occupies the subantarctic region of Chile,

102 Argentina and the Falkland Islands. Finally, O. venezuelensis occupies all Páramo

103 regions (Talamanca Cordillera, Venezuela, Colombia, Ecuador and northern Peru). 
104 The distributions of all Oreobolus Páramo species overlap with those of at least one

105 other congeneric species (Fig. 1). All Páramo species are found between 3000 and

$1064300 \mathrm{~m}$ a.s.l. while in the subantarctic regions, the altitude at which O. obtusangulus

107 is found decreases with increasing latitude, from $2400 \mathrm{~m}$ a.s.l. to sea level (Seberg

108 1988). The five South American species are clearly differentiated in terms of

109 morphology and, in common with most Cyperaceae, Oreobolus is both wind

110 pollinated and dispersed (Seberg 1988). Little is known about ploidy levels and

111 chromosome numbers in Oreobolus, with the only chromosome count for $O$.

112 obtusangulus ssp. obtusangulus $(2 \mathrm{n}=48$; Moore (1967)).

113 The five South American species of Oreobolus (O. cleefii, O. ecuadorensis, $O$.

114 goeppingeri, O. obtusangulus and O. venezuelensis) were sampled extensively across

115 their entire distribution range (Fig. 1). A total of 269 samples from 32 sampling

116 localities were obtained from both field collections (10 sampling localities) and

117 herbarium material (22 sampling localities) (Fig. 1 and Supp. Table 1). From each of

118 the ten field sampling localities, all within Colombia, two to ten fresh leaf samples

119 per species were collected, and their location was recorded using a handheld GPS

120 (Fig. 1, sampling localities 2 - 11). For sampling localities in Costa Rica, Ecuador,

121 Peru, Chile and Argentina (Fig. 1, sampling localities 1 and 12 - 32), herbarium

122 material was acquired from the Utrecht (U) and Leiden University (L) branches of

123 the National Herbarium of the Netherlands, Aarhus University Herbarium (AAU)

124 and the University of Reading Herbarium (RNG). For herbarium specimens, between

125 one and ten individuals per species were sampled from each sampling locality.

126 Coordinates were recorded from the herbarium specimens and checked for accuracy

127 using the NGA GEOnet Names Server (GNS) (http://geonames.nga.mil). Sampling 
128 localities are numbered 1 to 32 in a north to south direction. Sampling localities 1 to 12923 will be referred to as northern Andes - NA (Costa Rica, Colombia, Ecuador and 130 Peru) and 24 to 32 as southern Andes - SA (Chile and Argentina). Previously

131 published sequence data for $O$. cleefii, O. goeppingeri and O. venezuelensis (Chacón 132 et al. 2006) were also incorporated and assigned to their corresponding sampling 133 locality. Supplementary Table 2 presents the complete list of samples used in this 134 study together with their GenBank numbers.

\section{DNA extraction, amplification and sequencing}

136 Both silica-dried fresh leaf samples and herbarium material were pulverised using a 137 Mixer Mill (Retsch, Haan, Germany). Total genomic DNA from herbarium material 138 was isolated following the CTAB method of Doyle and Doyle (1990) and from 139 silica-dried samples with the DNeasy® Plant Mini Kit (QIAGEN, Manchester, UK) 140 following the manufacturer's protocol. The chloroplast region trnL-F was amplified 141 and sequenced using primers $\operatorname{trn} \mathrm{Lc}$ and $\operatorname{trn} \mathrm{Lf}$ for silica-dried material, and in 142 combination with internal primers $\operatorname{trn} \mathrm{Ld}$ and $\operatorname{trn} \mathrm{Le}$ for herbarium material (Taberlet 143 et al. 1991). For silica-dried material, the ITS region was amplified and sequenced 144 with external primers ITS5P and ITS8P (Möller and Cronk 1997). For herbarium 145 material, owing to the increased likelihood of the DNA being degraded, 146 amplification and sequencing were performed using external primers ITS5P and 147 ITS8P in combination with internal primers ITS2P and ITS3P (Möller and Cronk 148 1997), in order to amplify the shorter ITS1 and ITS2 regions in separate reactions. 149 The chloroplast regions $t r n \mathrm{H}-p s b \mathrm{~A}$ and $r p l 32-t r n \mathrm{~L}$ were amplified and sequenced 150 using primer pairs $\operatorname{trn} \mathrm{H}^{\mathrm{GUG}}$ (Tate and Simpson 2003)/psbA (Sang et al. 1997) and 
$151 \operatorname{trn} \mathrm{L}^{(\mathrm{UAG})} / r p l 32-\mathrm{F}$ (Shaw et al. 2007), respectively. For all reactions, $20 \mu 1 \mathrm{PCR}$ 152 reactions used the following proportions: $1 \mu \mathrm{l}$ of unquantified DNA, 1x Buffer 153 (Bioline, London, UK), $1 \mathrm{mM}$ dNTPs, 1.5 mM MgCl 2 (Bioline, London, UK), 0.75

$154 \mu \mathrm{M}$ of each forward and reverse primer, $4 \mu 1$ of combinatorial enhancer solution 155 (CES) and $0.05 \mathrm{U}$ of Taq polymerase (Bioline, London, UK). The amplification 156 cycle for all chloroplast regions ( $\operatorname{trn} \mathrm{L}-\mathrm{F}, \operatorname{trn} \mathrm{H}-p s b \mathrm{~A}$ and $r p l 32-t r n \mathrm{~L})$ consisted of 2 157 min at $94{ }^{\circ} \mathrm{C}$, followed by 30 cycles of $1 \mathrm{~min}$ at $94{ }^{\circ} \mathrm{C}, 1 \mathrm{~min}$ at $52^{\circ} \mathrm{C}$ and $1 \mathrm{~min}$ at 72 $158{ }^{\circ} \mathrm{C}$, finalising with $7 \mathrm{~min}$ at $72{ }^{\circ} \mathrm{C}$. For ITS, the amplification cycle consisted of $3 \mathrm{~min}$ 159 at $94{ }^{\circ} \mathrm{C}$, followed by 30 cycles of $1 \mathrm{~min}$ at $94{ }^{\circ} \mathrm{C}, 1 \mathrm{~min}$ at $55^{\circ} \mathrm{C}$ and $90 \mathrm{sec}$ at $72{ }^{\circ} \mathrm{C}$, 160 finalising with 5 min at $72{ }^{\circ} \mathrm{C}$. PCR products were purified with $2 \mu 1$ of ExoSAP-IT® 161 (USB Corporation, High Wycombe, UK) for $5 \mu 1$ of product. Sequencing reactions 162 for each primer used the BigDye ${ }^{\circledR}$ Terminator v3.1 chemistry (Applied 163 Biosystems ${ }^{\mathrm{TM}}$, Paisley, UK) and the manufacturer's protocol. Sequencing was 164 performed at the Edinburgh Genomics facility of the University of Edinburgh. No 165 double peaks were observed in the chromatograms of the ITS region and therefore it 166 was not necessary to clone.

\section{Matrix assembly and sequence alignment}

168 Contigs of forward and reverse sequences were assembled in Sequencher version 5.2

169 (Gene Codes Corporation, Ann Arbor, Michigan, USA). 230 ITS sequences, 169

170 trnL-F sequences, 128 trnH-psbA sequences and 190 rpl32-trnL sequences were

171 generated for this study (Supp. Table 2). The sequences were manually aligned using 172 Mesquite v2.75 (Maddison and Maddison 2014). Supplementary Table 3 describes 
173 number of individuals successfully sequenced per species per cluster/sampling

174 locality.

\section{Species phylogeny and timing of diversification}

176 The multispecies coalescent model implemented in *BEAST 2 (Heled and

177 Drummond 2012; Bouckaert et al. 2014) was used to estimate the phylogenetic

178 relationships amongst the five South American species of Oreobolus as well as their

179 divergence time. Only complete sequences were used for the species tree estimation

180 (ITS, $\operatorname{trn} \mathrm{L}-\mathrm{F}$, trnH-psbA and $r p l 32-t r n L$; Supp. Table 2). The analysis was run using

181 bModelTest (Bouckaert and Drummond 2017) which is a model selection tool

182 incorporated in BEAST 2 (Bouckaert et al. 2014) that uses a Bayesian framework

183 (reversible jump MCMC) to select the most appropriate substitution model while

184 simultaneously estimating the phylogeny. Phylogenetic reconstruction and

185 divergence time estimations were performed using BEAST v2.4.5 (Bouckaert et al.

186 2014). The tree model was linked for the three plastid regions because cpDNA does

187 not undergo recombination. The model of lineage-specific substitution rate variation

188 was set as a strict clock model for each dataset. A *BEAST analysis requires each

189 taxon to be associated with a species or taxonomic unit (Taxon Sets). These were

190 defined following current taxonomy but with O. obtusangulus divided into northern

191 and southern taxa (based upon results presented below). The diversification model

192 for the species tree was set to a calibrated Yule model (Heled and Drummond 2012)

193 with the population size model at its default setting. The root of the species tree was

194 clock calibrated using a prior with a normal distribution defined by a mean $(\mu)$ of

$1954.76 \mathrm{Ma}$ and a standard deviation $(\sigma)$ of 1.2 Ma. The age and error range correspond 
196 to those estimated for the crown node of the South American Oreobolus clade from a

197 dated phylogeny of the Schoeneae tribe using one fossil and one secondary

198 calibration (Gómez-Gutiérrez, 2016). A normal distribution was used on the root

199 because it is the most suitable for secondary calibrations (Ho and Phillips 2009). This

200 type of distribution allocates most of the probability density around the mean and

201 allows for symmetrical decrease towards the tails accounting for age error (Ho and

202 Phillips 2009). All other priors were left at their default settings.

203 Four independent MCMC runs of 250 million generations each were performed,

204 sampling every 25000 generations. Runs were combined and $75 \%$ of the samples

205 were discarded as burn-in. Adequate mixing and convergence were assessed using

206 Tracer v1.6.0 (Rambaut et al. 2013). A maximum clade credibility tree (MCC) from

207 the combined tree sets was annotated with common ancestor heights, 95\% HPD node

208 ages and posterior probability values (PP) on TreeAnnotator v2.1.2 (Rambaut and

209 Drummond 2015).

210 Haplotype definition and networks

211 Haplotypes were identified independently for the nuclear ribosomal region (ITS) and

212 the concatenated plastid regions ( $\operatorname{trn} \mathrm{L}-\mathrm{F}, \operatorname{trn} \mathrm{H}-p s b \mathrm{~A}$ and $r p l 32-t r n \mathrm{~L})$ in Microsoft

213 Excel (Microsoft Corporation, Washington DC, USA) using the Chloroplast PCR-

214 RFLP Excel macro (French 2003). For ITS, only samples successfully sequenced for

215 the whole region were included (Supp. Table 2). Likewise, for the concatenated

216 plastid regions, only samples successfully sequenced for all three regions were

217 considered (Supp. Table 2). Informative insertion/deletion events (indels) were

218 included in the analysis and coded as absent (0) or present (1) following the simple 
219 indel coding method of Simmons and Ochotenera (2000). Poly-T and poly-A length

220 polymorphisms, di-nucleotide repeats and ambiguously aligned regions were

221 excluded from subsequent analyses for all regions. Haplotype connection lengths

222 were calculated using Arlequin ver3.5 (Excoffier and Lischer 2010) and a minimum-

223 spanning tree was produced in Hapstar v0.5 (Teacher and Griffiths 2011).

224 NeighborNet networks - NN (Bryant and Moulton 2004) were also constructed for

225 both nuclear and concatenated plastid haplotypes using Splitstree 4 (Huson and

226 Bryant 2006). This method allows representation of conflicting signals in the data,

227 which might be due to incomplete lineage sorting or reticulate evolution (Bryant and

228 Moulton 2004; Huson and Bryant 2006). In the resulting network, conflicts are

229 represented by parallel edges connecting taxa. The NN networks used uncorrected-p

230 distances, which calculate the number of changes between each pair of haplotypes.

\section{Genetic diversity and structure}

232 Sampling localities were combined into clusters to increase the likelihood of

233 detecting phylogeographic signal (Fig. 1, Supp. Table 1). Clusters were defined

234 regardless of species classification, an approach justified by Gómez-Gutiérrez (2016;

235 see also results below) who showed poor phylogenetic resolution amongst the South

236 American species of Oreobolus. Fourteen clusters $(\mathrm{A}-\mathrm{N})$ were defined according to

237 geographic distance and ensuring the absence of any significant geographic barrier

238 between sampling localities within each cluster such as deep inter-Andean valleys.

239 Haplotype (h) and nucleotide $(\pi)$ diversities were calculated independently for each

240 cluster and each species in Arlequin ver3.5 (Excoffier and Lischer 2010). 
241 Additionally, haplotype richness (hr) was estimated for each species using

242 HIERFSTAT (Goudet 2005) in R version 3.2.3 (R Core Team 2015). This package uses

243 a rarefaction procedure set to 100 runs to correct for bias due to unequal sample

244 sizes. ITS sample size was standardised to 15 individuals while cpDNA sample size

245 was standardised to nine. Additionally, FST values between cluster pairs and species

246 pairs were calculated independently for ITS and the concatenated plastid regions

247 using Arlequin ver3.5 (Excoffier and Lischer 2010). NN networks for both nuclear

248 and concatenated plastid regions were constructed from the calculated $\mathrm{F}_{\mathrm{ST}}$ values.

249 For the cluster pairs, clusters $\mathrm{A}, \mathrm{K}$ and $\mathrm{N}$ were excluded from the analysis due to

250 their low sample sizes $(\mathrm{N} \leq 2)$. In the case of the species pairs, calculations were first

251 undertaken considering O. obtusangulus as one species and then with the northern

252 and southern populations considered as two different species.

253 To analyse the geographical structure of genetic variation, a spatial analysis of

254 molecular variance (SAMOVA) was performed independently for the nuclear and

255 concatenated plastid datasets (Dupanloup et al. 2002). SAMOVA identifies groups of

256 populations/clusters that are geographically homogeneous as well as maximising

257 genetic differentiation amongst them (Dupanloup et al. 2002). One hundred

258 annealing simulations were undertaken for each possible number of groups (ITS, $\mathrm{K}=$

$2592-13$; cpDNA, $\mathrm{K}=2-12$ ). The minimum number of groups (K) was chosen that

260 maximised the genetic differentiation amongst them $\left(\mathrm{F}_{\mathrm{CT}}\right)$. Subsequently, haplotype

261 (h) and nucleotide ( $\pi$ ) diversities were calculated for the resulting SAMOVA groups

262 in Arlequin ver3.5 (Excoffier and Lischer 2010). Likewise, haplotype richness (hr)

263 was estimated for each group using HIERFSTAT (Goudet 2005) in R version 3.2.3 (R

264 Core Team 2015). Similarly, to test if the phylogeographic structure had a 
265 phylogenetic component, two measures of genetic differentiation amongst clusters 266 were estimated using PeRmutCPSSR 2.0 (Pons and Petit 1996; Burban et al. 1999).

267 A distance matrix was calculated based on the number of mutational steps between 268 haplotypes $\left(\mathrm{N}_{\mathrm{ST}}\right)$ and on haplotype frequencies $\left(\mathrm{G}_{\mathrm{ST}}\right)$. Ten thousand permutations 269 were performed to assess if $\mathrm{N}_{\mathrm{ST}}$ was significantly higher than $\mathrm{G}_{\mathrm{ST}}$.

270 Additionally, variation in genetic structure was further examined for 1) all species, 2)

271 all clusters, 3) northern Andes clusters only, 4) clusters grouped by region (northern

272 Andes, southern Andes) and 5) SAMOVA groups using an analysis of molecular 273 variance (AMOVA) in Arlequin ver3.5 (Excoffier and Lischer 2010).

\section{RESULTS}

\section{Species phylogeny and timing of diversification}

276 The MCC tree for the combined tree sets (Fig. 2) shows O.cleefii, O. ecuadorensis, 277 O.goeppingeri and O. venezuelensis are recovered as monophyletic. The results 278 support the genetic differentiation between O. obtusangulus from the northern Andes 279 region (NA; Fig. 2) and O.obtusangulus from the southern Andes region (SA; Fig. 280 2). Oreobolus obtusangulus (SA) is sister to all remaining species. In the northern 281 Andean clade (NAC; $\mathrm{PP}=100 \%$ ), O. ecuadorensis, O. cleefii and O. obtusangulus 282 (NA) form a clade ( $\mathrm{PP}=75 \%)$ sister to another clade composed of $O$. goeppingeri and 283 O. venezuelensis ( $\mathrm{PP}=71 \%)$. Oreobolus cleefii and O.obtusangulus (NA) are 284 recovered as sister species $(\mathrm{PP}=87 \%)$. South American Oreobolus diverged c. 4.39 285 Ma (95\% HPD [1.96 - 6.97] Ma) during the Pliocene (Fig. 2). Subsequently, the 
286 NAC diversified into five species c. $0.44 \mathrm{Ma}(95 \%$ HPD $0.11-0.81] \mathrm{Ma})$ during the 287 Pleistocene (Fig. 2).

288 Haplotype definition and networks

289

290

291

292

293

294

295

296

297

298

299

\section{Nuclear ribosomal DNA}

A total of 197 individuals from 14 clusters $(A-N)$ were scored for ITS haplotypes, including individuals for all five species across their entire distribution range (Supp. Table 3). After exclusion of poly-T and poly-A length polymorphisms, di-nucleotide repeats and ambiguously aligned regions, $523 \mathrm{bp}$ of aligned sequences remained.

Thirty-nine polymorphic sites comprising 38 nucleotide substitutions and one indel defined thirty haplotypes. Of these, $22(73.3 \%)$ were species-specific while eight (26.7\%) were shared among species (Fig. 3, Supp. Table 4 and Supp. Fig. 1). There was no clear clustering according to current taxonomy evident in either the NeighborNet network (NN) (Fig. 3) or the minimum-spanning tree (MST) (Supp. Fig. 1), for example O. obtusangulus is not resolved in one group.

At a continental scale, haplotypes were geographically restricted with no shared haplotypes between the NA region and the SA (Fig. 3, Supp. Table 4 and Supp. Fig. 1). This geographic structure was evident in both the minimum-spanning tree (Supp. Fig. 1) and the NN network (Fig. 3). Within the NA sampling localities, patterns were more complicated. There are eight shared haplotypes evident in the MST (Supp. Fig. 1) and many edges in the NN Network (Fig. 3). Of the eight shared haplotypes, seven occur in O. obtusangulus. Furthermore Hn9, a haplotype shared between $O$. goeppingeri and $O$. obtusangulus, is located in the middle of the MST connecting the SA and NA haplotypes (Supp. Fig. 1). When not considering shared 
309 haplotypes, Hn12 and Hn14 found in O. goeppingeri are closer to those found in 310 other species than they are to other haplotypes of the same species as are $\operatorname{Hn} 28$ and 311 Hn30 in O. venezuelensis.

\section{Plastid DNA}

313 A total of 118 individuals from 13 clusters $(B-N)$ were successfully sequenced for 314 all three plastid markers (trnL-F, $\operatorname{trnH}-p s b \mathrm{~A}$ and $r p l 32-\operatorname{trn} \mathrm{L})$, including individuals 315 from all five species across most of their distribution range (Supp. Table 3). A

316 concatenated matrix of $2465 \mathrm{bp}$ of aligned sequences (trnL-F, $1040 \mathrm{bp}$; trn H-psbA, $317676 \mathrm{bp}$; rpl32-trnL, $749 \mathrm{bp}$ ) resulted after the exclusion of poly-T and poly-A length 318 polymorphisms, di-nucleotide repeats and ambiguously aligned regions. Forty 319 haplotypes were identified based on 141 polymorphic sites (trnL-F, 53; trnH-psbA, 32014 ; rpl32-trnL, 74) including 112 nucleotide substitutions and 28 indels. Thirty-four 321 haplotypes (85\%) were species-specific while six (15\%) were shared among species 322 (Fig. 4, Supp. Table 5 and Supp. Fig. 2). When only considering species-specific 323 haplotypes, both the MST and NN network showed some degree of clustering 324 according to taxonomy for three of the species, namely $O$. ecuadorensis, $O$. 325 goeppingeri and O. venezuelensis (Fig. 4 and Supp. Fig. 2).

326 As for ITS, there were no shared haplotypes between the NA and the SA regions 327 (Fig. 4, Supp. Table 5 and Supp. Fig. 2). This geographic structure was evident in 328 both the MST and the NN network (Fig. 4 and Supp. Fig. 2). There was low support 329 for groupings in the cpDNA network in the relationships amongst NA groups 330 compounded by the large number of possible unsampled haplotypes. The results of 
331 the cpDNA analysis were similar to those of ITS in showing a large number of edges

332 and of shared haplotypes.

\section{Genetic diversity and structure}

Species genetic structure

335 Molecular diversity indices for ITS and cpDNA for the five Oreobolus species,

336 including the two O. obtusangulus groups (NA and SA), are shown in Table 1.

337 Haplotype and nucleotide diversity was lowest in O.ecuadorensis and highest in $O$.

338 obtusangulus (Table 1). Similarly, haplotypic richness was lowest in O. ecuadorensis

339 and highest in O.obtusangulus. However, the high values in O.obtusangulus were

340 reduced when considering SA and NA populations of $O$. obtusangulus as separate

341 species (see Table 1).

342 Pairwise F $_{\text {ST }}$ values between all species pairs were significant for ITS and cpDNA

343 (ITS: $p<0.001$; cpDNA: $p<0.05$ ), with the exception of $O$. cleefii and $O$.

344 obtusangulus (NA) for cpDNA ( $\left.\mathrm{F}_{\mathrm{ST}}=-0.020\right)$ (Table 2, Supp. Figs $\left.3-4\right)$.

345 Oreobolus ecuadorensis is consistently differentiated from the other species in both

346 ITS and cpDNA (Table 2, Supp. Figs 3 -4). The NN, based on FST values showed

347 that when considering $O$. obtusangulus as one species, it is reconstructed in the

348 middle of the network and its placement is poorly resolved in both ITS and cpDNA

349 NN networks (Supp. Figs 3a-4a). In contrast, when considering northern and

350 southern groups separately, O. obtusangulus (SA) is clearly different from other

351 Oreobolus species, whereas $O$. obtusangulus (NA) has affinities with $O$. cleefii. The

352 conflicting signal between the latter two species (i.e., multiple parallel edges) is

353 evident in both cpDNA and ITS NN networks (Supp. Figs $3 b-4 b$ ). Oreobolus 
354 goeppingeri and $O$. venezuelensis are well differentiated in cpDNA but not in ITS 355 where they appeared in the centre of the networks with multiple connections to the 356 other species (Supp. Figs $3-4)$.

\section{Cluster genetic structure}

358 The results of the AMOVA showed that although differentiation amongst species 359 was significant (ITS, $\mathrm{F}_{\mathrm{ST}}=0.30, p<0.001$; cpDNA, $\mathrm{F}_{\mathrm{ST}}=0.48, p<0.001$ ), within 360 species variation accounted for $70 \%$ for ITS and $52 \%$ for cpDNA (Table 3 ).

361 Similarly, separation into geographic clusters only explained 43\% (ITS) and 37\% 362 (cpDNA) of the variation.

363 The SAMOVA for both ITS and cpDNA indicated three groups (I - III; Supp. Table 364 8, Supp. Figs $1-2)$ as the number of genetic clusters $(K)$ that maximised genetic 365 differentiation amongst groups while minimising the number of single-cluster groups 366 (ITS, $\mathrm{F}_{\mathrm{CT}}=0.622, p<0.001 ;$ cpDNA, $\left.\mathrm{F}_{\mathrm{CT}}=0.426, p<0.001\right)$. For ITS, group I 367 included all NA clusters (A - J) while groups II (K, L, N) and III (M) included the 368 SA ones (Supp. Table 8, Supp. Fig. 1). For cpDNA, group I included all NA clusters 369 plus the northernmost SA cluster (K), while groups II (L, N) and III (M) included the 370 rest (Supp. Table 8, Supp. Fig. 2). SAMOVA groups explained slightly more of the 371 genetic structure (ITS, $\mathrm{F}_{\mathrm{CT}}=0.62, p<0.001$; $\left.\mathrm{cpDNA}, \mathrm{F}_{\mathrm{CT}}=0.43, p<0.001\right)$ than the 372 NA versus SA continental divide (ITS, $\mathrm{F}_{\mathrm{CT}}=0.60, p<0.001 ; \mathrm{cpDNA}, \mathrm{F}_{\mathrm{CT}}=0.36, p$ $373<0.001)($ Table 3). Molecular diversity indices calculated for the SAMOVA groups 374 are presented in Table 4. Significant phylogeographic structure was indicated by the 375 significantly higher values of $\mathrm{N}_{\mathrm{ST}}\left(\mathrm{ITS}, \mathrm{N}_{\mathrm{ST}}=0.605 ; \mathrm{cpDNA}, \mathrm{N}_{\mathrm{ST}}=0.406\right)$ 376 compared to $\mathrm{G}_{\mathrm{ST}}\left(\mathrm{ITS}, \mathrm{G}_{\mathrm{ST}}=0.262 ; \mathrm{cpDNA}, \mathrm{G}_{\mathrm{ST}}=0.156 ; p<0.01\right)$. 


\section{Timing of diversification}

379 The dated species tree presented here (Fig. 2) indicates younger diversification dates

380 than those presented by Chacón et al. (2006), which is expected because divergence

381 dates estimated from a species tree will generally be younger than those estimated

382 from a gene tree (Drummond and Bouckaert 2015). Our species phylogeny indicates

383 that the most recent common ancestor of the South American Oreobolus diverged

384 4.39 Ma (95\% HPD [1.96 - 6.97] Ma) during the late Miocene - early Pliocene.

385 Subsequently, the northern Andean clade (NAC) appears to have diversified from

$3860.44 \mathrm{Ma}(95 \%$ HPD $[0.11-0.81] \mathrm{Ma})$. This indicates that the expansion and

387 contraction of Páramo islands during the glacial cycles of the Quaternary may have

388 played a role in diversification in the northern Andes (see last section of the

389 discussion) (van der Hammen 1974; Simpson 1975; van der Hammen and Cleef

390 1986; Hooghiemstra and van der Hammen 2004).

\section{Genetic diversity and structure}

392 Our results reveal a complex evolutionary history for the five South American

393 species of Oreobolus. Species relationships were difficult to estimate, indicating

394 either interspecific gene flow and/or incomplete lineage sorting (Naciri and Linder

395 2015). Haplotype and nucleotide diversity were high for both ITS and cpDNA for all

396 species except O. ecuadorensis (Table 1). Additionally, shared haplotypes were

397 observed in both ITS (27\%) and cpDNA (15\%). This intricate history is also evident 
398 in the MST and NN networks for both ITS and cpDNA (Figs. 3 - 4 and Supp. Figs. 1

$399-2)$.

400 The high degree of complexity observed amongst these species contrasts with the

401 morphological characters that distinguish them. Inconsistencies between

402 morphological characteristics and genetic patterns can arise due to high levels of

403 plasticity of morphological characters or parallel adaptations to local conditions

404 resulting in the same morphology, which might be the case for O.obtusangulus. The

405 data presented here indicate that the two subspecies of $O$. obtusangulus represent

406 morphologically cryptic species. Britton et al. (2014) have described another

407 example of cryptic speciation within the Schoeneae in the South African species

408 Tetraria triangularis. These authors found at least three intraspecific lineages that

409 qualified as cryptic species based on their genetic distinctiveness and subtle

410 morphological differentiation. Furthermore, cryptic lineages have also been found in

411 otherwise morphologically indistinguishable taxa within the Páramo genus Loricaria

412 (Asteraceae) (Koláŕ et al. 2016).

413 Nonetheless, convergent morphological evolution does not appear to satisfactorily

414 account for the genetic patterns observed in many South American species of

415 Oreobolus, which may result from incomplete lineage sorting (ILS) and/or

416 hybridization. Given the recent Pliocene diversification of both the northern and

417 southern Andean clades of Oreobolus (Fig. 2), lineage sorting may not have been

418 fully completed. Previous studies have indicated ILS in recently diverged groups,

419 particularly when effective population sizes are large (Maddison and Knowles 2006;

420 Jakob and Blattner 2006; Degnan and Rosenberg 2009; Cutter 2013). Furthermore,

421 under a scenario of ILS, it is expected that different genes would have different 
422 coalescence times. Haploid plastid genes have a lower effective population size than

423 nuclear genes and thus would coalesce faster (Schaal and Olsen 2000; Naciri and

424 Linder 2015). Faster coalescence would be translated into an increased

425 correspondence between the genetic relationships recovered with plastid genes and

426 currently recognised taxonomic species. Our results support this scenario because

427 cpDNA better differentiates taxonomic species than ITS for O.ecuadorensis, $O$.

428 goeppingeri and O. venezuelensis (Figs. 3 - 4 and Supp. Figs. 1 - 2).

429 However, species relationships may be obscured by ongoing gene flow as patterns of

430 ILS are difficult to disentangle from those of historic hybridization. Two species

431 pairs, Oreobolus cleefii and O.obtusangulus (NA), and O. goeppingeri and $O$.

432 venezuelensis, show patterns indicative of ILS and/or hybridization. Firstly,

433 Oreobolus cleefii and O. obtusangulus (NA) show contrasting patterns between

434 nuclear (ITS) and cpDNA haplotypes (Figs. 3 - 4 and Supp. Figs. 1 - 2) possibly due

435 to chloroplast capture and simultaneous nuclear introgression (Abbott et al. 2013).

436 These closely related species naturally occur in sympatry in all of the sampled

437 localities (Fig. 1) and show an overlap in morphological characters (Seberg 1988). In

438 fact, morphological similarities previously lead Seberg (1988) to suggest that $O$.

439 cleefii should be reduced to synonymy under O. obtusangulus subsp. unispicus, the

440 northern Andean subspecies of O.obtusangulus. Secondly, the two most widespread

441 species in the Páramo, O. goeppingeri and O. venezuelensis, also naturally occur in

442 sympatry in all sampled localities (Fig. 1). These species also show complicated

443 genetic patterns, combining high levels of diversity with shared haplotypes (Figs. 3

444 and 4) and conflicting phylogenetic relationships (Supp. Figs. 3 - 4 with other

445 northern Andean species). A possible explanation is that the widespread nature of 
446 these species provided greater opportunities for intra, and interspecific mixing

447 compared with more range-restricted species, which exhibit a similar pattern of

448 haplotype sharing, albeit on a smaller scale (Supp. Figs. 1 - 2).

449 Current gene flow would be expected to result in F1 hybrids that would exhibit 450 heterozygosity in ITS, but this was not observed in any Oreobolus species, although

451 such heterozygosity may no longer be evident in older hybrids. While the presence of

452 later generations of hybrids or backcrosses cannot be excluded, the lack of

453 heterozygosity in ITS and the presence of shared haplotypes recovered in multiple

454 pairs of individuals from all species is more suggestive of a stochastic process likely

455 related to lineage sorting. Therefore, although gene flow cannot be ruled out and may

456 have a role in some situations (e.g. Oreobolus cleefii and O. obtusangulus see

457 below), we suggest incomplete lineage sorting in a recently diversified group is also

458 part of the explanation for the complex patterns observed in the South American

459 species of Oreobolus. A recent phylogeographic study of the Australian alpine Poa

460 (Poaceae) describes a similar pattern of problematic recovery of species relationships

461 associated with a putatively young ecosystem and a Pleistocene radiation following

462 long-distance dispersal to Australia (Griffin and Hoffmann 2014). This study also

463 favoured ILS rather than ongoing gene flow as the likely process behind the

464 observed pattern based on the widespread genetic similarity and recent divergence

465 times.

466 The results of the AMOVAs revealed that neither clustering into currently defined

467 taxonomic species (Mora-Osejo 1987; Seberg 1988) nor into our pre-defined

468 geographic clusters (Fig. 1, Supp. Table 1) described the distribution of genetic

469 diversity, only explaining 30\% (ITS)/48\% (cpDNA) and 43\% (ITS)/37\% (cpDNA), 
470

471

472

473

474

475

476

477

478

479

480

481

482

483

484

485

486

487

488

489

490

491

492

493

respectively (Table 3 ). Rather, the SAMOVA suggested that an a posteriori geographic arrangement better explained genetic diversity $(62 \%$ for ITS and $43 \%$ for cpDNA, Table 3). Thus, the observed patterns of genetic diversity are likely to be the result of complex interactions between some species over various geographic distances.

At a continental scale there is evidence of geographic structure in Oreobolus species, (Figs. 1 -2, Supp. Figs. $1-2$ ), suggested by a higher value of $\mathrm{N}_{\mathrm{ST}}$ compared to GST $(p<0.01)$, indicating that haplotypes in the same cluster are on average more closely related than distinct haplotypes from different clusters. The clearest geographic break apparent in Oreobolus is between the northern Andes (NA) and southern Andes (SA). This pattern is evident in both chloroplast and nuclear regions, although the pattern is much stronger in ITS (Figs. $1-2$, Supp. Figs. $1-2$ ). The arid central Andes are likely to impose a barrier to dispersal and gene flow, but the position of the north-south break is unclear. SAMOVA groups clearly identify the NA/SA disjunction in ITS but not in the plastid region where cluster $\mathrm{K}$ is grouped with the northern Andean clusters (Supp. Table 8, Supp. Figs. 1 - 2). The latter is also evident in the cpDNA NN where the distance between haplotypes is shorter than in the NN for ITS (Figs. $1-2$ ). The incongruence between ITS and plastid regions may suggest mixing between the SAC and NAC in cluster $\mathrm{K}$, resulting from long distance dispersal events. Cluster K is separated from both NA clusters and other SA clusters by a substantial distance and possesses unique haplotypes at both ITS and plastid regions (Supp. Tables $4-5$ ).

Additional structure is evident at regional scales within the NAC and appears to be associated with putative geographic barriers to gene flow. Pairwise FST values 
494 calculated for ITS showed that clusters B and J were significantly differentiated from

495 all other sites, regardless of the geographic distances (Fig. 5, Supp. Table 7). These

496 two clusters are separated from all other NA clusters by inter-Andean valleys of

497 seasonally dry tropical forest. Cluster B is isolated from the rest by the dry

498 Chicamocha Canyon while cluster J is separated from the other NA clusters by the

499 Marañón Valley (Fig. 1). Särkinen et al. (2012) suggested that biome heterogeneity

500 across the Andes represented a strong barrier to dispersal within island-like

501 ecosystems. This is particularly relevant when deep valleys segment the mountain

502 ranges, as is the case here. In addition, for O. venezuelensis, clusters $\mathrm{H}$ and $\mathrm{I}$ have

503 ITS haplotypes distinct from others in the species, namely Hn28 and Hn30 (Fig. 1,

504 Supp. Fig. 1). These haplotypes are distributed in the southernmost part of these

505 species' distribution range and their differentiation from species-specific haplotypes

506 distributed in the northernmost areas (Hn26, Hn27 and Hn28) further supports the

507 observed phylogeographic structure and possible pattern of isolation by distance.

508 Genetic patterns in the light of Quaternary glacial-interglacial cycles.

509 Our dated tree (Fig. 2) is consistent with Quaternary diversification in the NAC, and

510 high levels of molecular diversity for both nuclear and plastid regions, as well as the

511 high number of unsampled cpDNA haplotypes in our dataset, are concordant with a

512 scenario of expansion and contraction of Páramo islands during the glacial cycles of

513 the Quaternary (Table 4, Supp. Table 8 and Supp. Fig. 2). SAMOVA analysis failed

514 to identify any clear groupings within the NAC (Supp. Table 8, Supp. Figs. 1 - 2)

515 and variation amongst NA clusters was moderate and mostly explained by within

516 cluster variation (ITS, 86\%; cpDNA, 79\%; Table 3). Vicariance events would allow 
517 for differentiation of populations and diversification, through selection and drift. If

518 reproductive isolation is incomplete, subsequent expansion events may have allowed

519 gene flow amongst nearby populations and potentially even amongst species.

520 Repeated vicariance and contact, which would be expected from Quaternary glacial

521 cycles, would generate complex genetic patterns, with species sharing haplotypes.

522 Such patterns are evident in Oreobolus, with a few widespread haplotypes amongst

523 species apparently giving rise to geographically restricted haplotypes (Supp. Figs. 1

524 -2). Similar patterns have been reported for the afro-alpine populations of Arabis

525 alpina where several cycles of range contraction and expansion caused by the glacial

526 cycles of the Quaternary may have shaped intra-specific distribution of genetic

527 diversity (Assefa et al. 2007). In the same way, cluster M in the SA region is a

528 divergent genetic group for both ITS and cpDNA in SAMOVA analyses (Supp. Figs.

$5291-2)$. Molecular diversity indices for this cluster showed low haplotype diversity

530 and high nucleotide diversity in ITS, and high haplotype diversity and low nucleotide

531 diversity in cpDNA (Supp. Table 8). A possible explanation for this pattern might be

532 that these populations underwent a bottleneck during isolation resulting in a low

533 number of divergent haplotypes. During the glacial cycles of the Quaternary ice

534 sheets covered extensive areas and generated massive fragmentation and restriction

535 in the distribution of southern Andean plants producing pockets of refugial

536 populations (e.g. Markgraf et al. 1995). Although a scenario of Pleistocene refugia

537 has already been proposed for other southern Andean plants (e.g. Tremetsberger et

538 al. 2009) further work would be required to assess the potential for refugial

539 populations in O. obtusangulus (SA). 
540 Glacial cycles may have also had an impact at the inter-specific level. Oreobolus

541 ecuadorensis has the lowest molecular diversity indices for both ITS and cpDNA

542 (Table 1) and is one of the most geographically restricted species, found only in

543 Ecuador and northern Peru (Fig. 1). Such patterns may arise through a severe

544 bottleneck followed by a population expansion likely imposed by the glacial cycles

545 of the Quaternary (Templeton 1998; Hewitt 2004). Ecuador and Peru have the

546 highest percentage of permanent snow and therefore interglacial periods may have

547 greatly reduced the size of the populations of $O$. ecuadorensis, reducing its genetic

548 diversity. Following the Last Glacial Maximum (LGM), population expansion may

549 have occurred with new mutations likely to accumulate as the species occupied new

550 areas. New haplotypes were thereby produced, diverging from the founder

551 population by only a few nucleotides. At the same time, the strong impact of

552 interglacial periods is evident in the clear differentiation of $O$.ecuadorensis from all

553 other species (Table 2, Supp. Figs. 3 -4).

554 There was no clear evidence of ongoing hybridization but historic hybridization

555 between sympatric sister species $O$. cleefii and $O$. obtusangulus (NA) may have been

556 facilitated by periods of isolation and divergence during the glacial cycles of the

557 Quaternary. Secondary contact zones can form from long-distance dispersal events,

558 leading to interspecific hybridization, such as that proposed by Gizaw et al. (2016)

559 for two co-occurring sister species of Carex from a similar tropical alpine ecosystem

560 in East Africa. We suggest a similar scenario for O. cleefii and O. obtusangulus

561 (NA), with renewed contact occurring following isolation during interglacial periods

562 in the Quaternary (van der Hammen 1974). 
564 This is one of a few studies to investigate genetic relationships both within and

565 between species in a recently diverged Páramo genus and hence it provides a

566 significant contribution to the understanding of the historical assembly of the Páramo

567 flora. The results presented here are consistent with a role for contraction and

568 expansion of Páramo islands during glacial cycles in the diversification of Oreobolus

569 species. ILS appears to have played a role in the complex genetic patterns observed

570 amongst these recently diverged Oreobolus species. ILS rather than recent

571 hybridization is suggested by the lack of heterozygosity in ITS, but a role for

572 historical hybridization cannot be discounted, particularly in several situations where

573 the species are sympatric. Additional work incorporating more extensive sampling of

574 individuals and assessing additional genetic data will be required to more accurately

575 estimate patterns of historical demography of Oreobolus, which could bring further

576 insight into the population dynamics of Páramo plants. 
579 The authors declare that they have no conflict of interest.

\section{DECLARATION OF AUTHORSHIP}

MCGG and JER devised the project. LEN assisted with data analyses. MCGG

drafted the text, with substantial contributions by JER, RTP and LEN. All authors

contributed to final editing.

\section{REFERENCES}

Abbott R, Albach D, Ansell S, et al (2013) Hybridization and speciation. J Evol Biol 26:229-246. doi: 10.1111/j.1420-9101.2012.02599.x

Arnold ML (1997) Natural hybridization and evolution. Oxford University Press, New York

Assefa A, Ehrich D, Taberlet P, et al (2007) Pleistocene colonization of afro-alpine "sky islands" by the arctic-alpine Arabis alpina. Heredity 99:133-142. doi: 10.1038/sj.hdy.6800974

Bouckaert R, Drummond AJ (2017) bModelTest: Bayesian phylogenetic site model averaging and model comparison. BMC Evolutionary Biology 17:1-11. doi: 10.1186/s12862-017-0890-6

Bouckaert R, Heled J, Kühnert D, et al (2014) BEAST 2: A Software Platform for Bayesian Evolutionary Analysis. PLoS Comput Biol 10:e1003537-6. doi: 10.1371/journal.pcbi.1003537

Britton MN, Hedderson TA, Verboom GA (2014) Topography as a driver of cryptic speciation in the high-elevation cape sedge Tetraria triangularis (Boeck.) C. B. Clarke (Cyperaceae: Schoeneae). Molecular Phylogenetics and Evolution 77:96109. doi: 10.1016/j.ympev.2014.03.024 
Bryant D, Moulton V (2004) Neighbor-Net: An Agglomerative Method for the Construction of Phylogenetic Networks. Molecular Biology and Evolution 21:255-265. doi: 10.1093/molbev/msh018

Burban C, Petit R, Carcreff E, Jactel H (1999) Rangewide variation of the maritime pine bast scale Matsucoccus feytaudi Duc. (Homoptera: Matsucoccidae) in relation to the genetic structure of its host. Mol Ecol 8:1593-1602.

Buytaert W, Cuesta-Camacho F, Tobón C (2010) Potential impacts of climate change on the environmental services of humid tropical alpine regions. Global Ecology and Biogeography 20:19-33. doi: 10.1111/j.1466-8238.2010.00585.x

Chacón J, Madriñán S, Chase MW, Bruhl JJ (2006) Molecular phylogenetics of Oreobolus (Cyperaceae) and the origin and diversification of the American species. Taxon 55:359-366.

Cutter AD (2013) Integrating phylogenetics, phylogeography and population genetics through genomes and evolutionary theory. Molecular Phylogenetics and Evolution 69:1172-1185. doi: 10.1016/j.ympev.2013.06.006

Degnan JH, Rosenberg NA (2009) Gene tree discordance, phylogenetic inference and the multispecies coalescent. Trends in Ecology \& Evolution 24:332-340. doi: 10.1016/j.tree.2009.01.009

Doyle J, Doyle JL (1990) Isolation of plant DNA from fresh tissue. Focus 12:13-15.

Drummond AJ, Bouckaert RR (2015) Bayesian Evolutionary Analysis with BEAST, First. Cambridge University Press, Cambridge

Dupanloup I, Schneider S, Excoffier L (2002) A simulated annealing approach to define the genetic structure of populations. Mol Ecol 11:2571-2581.

Excoffier L, Lischer HEL (2010) Arlequin suite ver 3.5: a new series of programs to perform population genetics analyses under Linux and Windows. Molecular Ecology Resources 10:564-567. doi: 10.1111/j.1755-0998.2010.02847.x

French GC (2003) Conservation genetics of British Euphrasia L. University of Edinburgh and Royal Botanic Garden Edinburgh, Edinburgh

Gizaw A, Kebede M, Nemomissa S, et al (2013) Phylogeography of the heathers Erica arborea and E. trimera in the afro-alpine "sky islands" inferred from AFLPs and plastid DNA sequences. Flora 208:453-463. doi: 10.1016/j.flora.2013.07.007

Gizaw A, Wondimu T, Mugizi TF, et al (2016) Vicariance, dispersal, and hybridization in a naturally fragmented system: the afro-alpine endemics Carex monostachya and C. runssoroensis (Cyperaceae). Alpine Botany 126:59-71. doi: $10.1007 / \mathrm{s} 00035-015-0162-2$

Goudet J (2005) Hierfstat, a package for R to compute and test hierarchical F- 

statistics. Molecular Ecology Notes 5:184-186. doi: doi: 10.1111/j.1471-8278 $.2004 .00828 . \mathrm{x}$

Gómez-Gutiérrez MC (2016) Evolution in the high-altitude Páramo ecosystem. The University of Edinburgh PhD thesis.

Graham A (2009) The Andes: a geological overview from a biological perspective. Annals of the Missouri Botanical Garden 96:371-385. doi: 10.3417/2007146

Griffin PC, Hoffmann AA (2014) Limited genetic divergence among Australian alpine Poa tussock grasses coupled with regional structuring points to ongoing gene flow and taxonomic challenges. Annals of Botany 113:953-965. doi: 10.1093/aob/mcu017

Heled J, Drummond AJ (2012) Calibrated Tree Priors for Relaxed Phylogenetics and Divergence Time Estimation. Systematic Biology 61:138-149. doi: $10.1093 /$ sysbio/syr087

Hewitt GM (2004) Genetic consequences of climatic oscillations in the Quaternary. Philosophical Transactions of the Royal Society B: Biological Sciences 359:183-195. doi: 10.1098/rstb.2003.1388

Ho SYW, Phillips MJ (2009) Accounting for calibration uncertainty in phylogenetic estimation of evolutionary divergence times. Systematic Biology 58:367-380. doi: 10.1093/sysbio/syp035

Hooghiemstra H, van der Hammen T (2004) Quaternary Ice-Age dynamics in the Colombian Andes: developing an understanding of our legacy. Philosophical Transactions of the Royal Society B: Biological Sciences 359:173-181. doi: 10.1098/rstb.2003.1420

Hooghiemstra H, Wijninga VM, Cleef AM (2006) The paleobotanical record of Colombia: implications for biogeography and biodiversity. Annals of the Missouri Botanical Garden 93:297-324. doi: 10.3417/00266493(2006)93[297:TPROCI]2.0.CO;2

Huson DH, Bryant D (2006) Application of phylogenetic networks in evolutionary studies. Molecular Biology and Evolution 23:254-267. doi: 10.1093/molbev/msj030

Jakob SS, Blattner FR (2006) A chloroplast genealogy of Hordeum (Poaceae): longterm persisting haplotypes, incomplete lineage sorting, regional extinction, and the consequences for phylogenetic inference. Molecular Biology and Evolution 23:1602-1612. doi: 10.1093/molbev/ms1018

Kadu CAC, Konrad H, Schueler S, et al (2013) Divergent pattern of nuclear genetic diversity across the range of the Afromontane Prunus africana mirrors variable climate of African highlands. Annals of Botany 111:47-60. doi: $10.1093 / \mathrm{aob} / \mathrm{mcs} 235$ 
Kebede M, Ehrich D, Taberlet P, et al (2007) Phylogeography and conservation genetics of a giant lobelia (Lobelia giberroa) in Ethiopian and Tropical East African mountains. Mol Ecol 16:1233-1243. doi: 10.1111/j.1365294X.2007.03232.x

Kolář F, Dušková E, Sklenář P (2016) Niche shifts and range expansions along cordilleras drove diversification in a high-elevation endemic plant genus in the tropical Andes. Mol Ecol 25:4593-4610. doi: 10.1111/mec.13788

Luteyn JL (1999) Páramos: a checklist of plant diversity, geographical distribution, and botanical literature, First. The New York Botanical Garden Press, New York

Maddison WP, Knowles LL (2006) Inferring phylogeny despite incomplete lineage sorting. Systematic Biology 55:21-30. doi: 10.1080/10635150500354928

Maddison WP, Maddison DR (2014) Mesquite: a modular system for evolutionary analysis. Version 2.75. Available at http://mesquiteproject.org. mesquiteproject.org.

Madriñán S, Cortés AJ, Richardson JE (2013) Páramo is the world's fastest evolving and coolest biodiversity hotspot. Frontiers in Genetics 4:1-7. doi: 10.3389/fgene.2013.00192/abstract

Markgraf V, McGlone M, Hope G (1995) Neogene paleoenvironmental and paleoclimatic change in southern temperate ecosystems - a southern perspective. Trends in Ecology \& Evolution 10:143-147. doi: 10.1016/S01695347(00)89023-0

Moore DM (1967) Chromosome numbers of Falkland Islands Angiosperms. British Antarctic Survey Bulletin 14:69-82.

Mora-Osejo LE (1987) Estudios morfológicos, autoecológicos y sistemáticos en Angiospermas. Academia Colombiana de Ciencias Exactas, Físicas y Naturales, Bogotá, DE

Möller M, Cronk QCB (1997) Origin and relationships of Saintpaulia (Gesneriaceae) based on ribosomal DNA internal transcribed spacer (ITS) sequences. American Journal of Botany 84:956-965.

Naciri Y, Linder HP (2015) Species delimitation and relationships: The dance of the seven veils. Taxon 64:3-16. doi: 10.12705/641.24

Pons O, Petit RJ (1996) Measuring and testing genetic differentiation with ordered versus unordered alleles. Genetics 144:1237-1245.

R Core Team (2015) R: A language and environment for statistical computing. R Foundation for Statistical Computing, Vienna, Austria. Available at https://www.R-project.org/. httpswww.R-project.org

Rambaut A, Drummond AJ (2015) TreeAnnotator: MCMC output analysis. Version 
2.3.0. Available at http://tree.bio.ed.ac.uk/software/beast. httptree.bio.ed.ac.uksoftware

Rambaut A, Suchard MA, Xie W, Drummond AJ (2013) Tracer: MCMC trace analysis tool. Version 1.6.0. Available at http://tree.bio.ed.ac.uk/software/tracer. httptree.bio.ed.ac.uksoftware

Sang T, Crawford D, Stuessy T (1997) Chloroplast DNA phylogeny, reticulate evolution, and biogeography of Paeonia (Paeoniaceae). American Journal of Botany 84:1120-1136.

Särkinen T, Pennington RT, Lavin M, et al (2012) Evolutionary islands in the Andes: persistence and isolation explain high endemism in Andean dry tropical forests. Journal of Biogeography 39:884-900. doi: 10.1111/j.1365-2699.2011.02644.x

Schaal BA, Hayworth DA, Olsen KM, et al (1998) Phylogeographic studies in plants: problems and prospects. Mol Ecol 7:465-474. doi: 10.1046/j.1365294x.1998.00318.x

Schaal BA, Olsen KM (2000) Gene genealogies and population variation in plants. Proc Natl Acad Sci USA 97:7024-7029.

Seberg O (1988) Taxonomy, phylogeny, and biogeography of the genus Oreobolus R.Br. (Cyperaceae), with comments on the biogeography of the South Pacific continents. Botanical Journal of the Linnean Society 96:119-195. doi: 10.1111/j.1095-8339.1988.tb00632.x

Shaw J, Lickey EB, Schilling EE, Small RL (2007) Comparison of whole chloroplast genome sequences to choose noncoding regions for phylogenetic studies in Angiosperms: the tortoise and the hare III. American Journal of Botany 94:275288. doi: 10.3732 ajb.94.3.275

Simmons MP, Ochoterena H (2000) Gaps as characters in sequence-based phylogenetic analyses. Systematic Biology 49:369-381.

Simpson BB (1975) Pleistocene changes in the flora of the high tropical Andes. Paleobiology 1:273-294. doi: 10.2307/2400369

Taberlet P, Gielly L, Pautou G, Bouvet J (1991) Universal primers for amplification of three non-coding regions of chloroplast DNA. Plant Mol Biol 17:1105-1109.

Tate JA, Simpson BB (2003) Paraphyly of Tarasa (Malvaceae) and diverse origins of the polyploid species. Systematic Botany 28:723-737. doi: 10.2307/25063919?ref=search-gateway:ab20df06ffd5b47899780d1c7b361d21

Teacher AGF, Griffiths DJ (2011) HapStar: automated haplotype network layout and visualization. Molecular Ecology Resources 11:151-153. doi: 10.1111/j.17550998.2010.02890.x

Templeton AR (1998) Nested clade analyses of phylogeographic data: testing 
hypotheses about gene flow and population history. Mol Ecol 7:381-397.

751

752

753

754

755

756

757

758

759

760

761

762

763

764

765

766
Tremetsberger K, Urtubey E, Terrab A, et al (2009) Pleistocene refugia and polytopic replacement of diploids by tetraploids in the Patagonian and Subantarctic plant Hypochaeris incana (Asteraceae, Cichorieae). Mol Ecol 18:3668-3682. doi: 10.1111/j.1365-294X.2009.04298.x

van der Hammen T (1974) The Pleistocene changes of vegetation and climate in tropical South America. Journal of Biogeography 1:3-26.

van der Hammen T, Cleef AM (1986) Development of the high Andean Páramo flora and vegetation. In: Vuilleumier F, Monasterio M (eds) High Altitude Tropical Biogeography, First. Oxford University Press, Inc, New York, pp 153-201

Vásquez DLA, Balslev H, Hansen MM, et al (2016) Low genetic variation and high differentiation across sky island populations of Lupinus alopecuroides (Fabaceae) in the northern Andes. Alpine Botany 1-8. doi: 10.1007/s00035-0160165-7

Wondimu T, Gizaw A, Tusiime FM, et al (2013) Crossing barriers in an extremely fragmented system: two case studies in the afro-alpine sky island flora. Plant Syst Evol 300:415-430. doi: 10.1007/s00606-013-0892-9 
Table 1. Molecular diversity indices for ITS and cpDNA (trnL-F, trnH-psbA and rpl32-trnL) for each species. N: number of individuals; $\mathrm{H}$ : number of haplotypes; hr: haplotype richness (ITS, rarefied to a minimum sample of 15; cpDNA, rarefied to a minimum sample of 9 ); $h$, haplotype diversity $( \pm$ SD); $\pi$, nucleotide diversity ( \pm SD). A, O. obtusangulus considered as one species; B, O. obtusangulus considered as two species.

\begin{tabular}{|c|c|c|c|c|c|}
\hline Species & $N$ & $\mathrm{H}$ & $\mathrm{hr}$ & $\mathrm{h}$ & $\pi \times 100$ \\
\hline \multicolumn{6}{|l|}{ ITS } \\
\hline O. cleefii & 15 & 5 & 5.00 & $0.70 \pm 0.11$ & $0.45 \pm 0.30$ \\
\hline O. ecuadorensis & 24 & 4 & 3.12 & $0.31 \pm 0.12$ & $0.01 \pm 0.10$ \\
\hline O. goeppingeri & 75 & 12 & 6.09 & $0.79 \pm 0.03$ & $1.15 \pm 0.61$ \\
\hline \multicolumn{6}{|l|}{ O. obtusangulus } \\
\hline NA & 23 & 8 & 6.12 & $0.68 \pm 0.10$ & $0.56 \pm 0.35$ \\
\hline SA & 33 & 5 & 3.88 & $0.64 \pm 0.06$ & $2.25 \pm 1.16$ \\
\hline Combined & 56 & 13 & 6.59 & $0.82 \pm 0.03$ & $2.76 \pm 1.39$ \\
\hline O. venezuelensis & 27 & 7 & 5.02 & $0.63 \pm 0.10$ & $1.49 \pm 0.80$ \\
\hline \multicolumn{6}{|l|}{ cpDNA } \\
\hline O. cleefii & 9 & 4 & 4.00 & $0.78 \pm 0.11$ & $1.96 \pm 1.07$ \\
\hline O. ecuadorensis & 29 & 5 & 3.54 & $0.72 \pm 0.05$ & $0.11 \pm 0.07$ \\
\hline O. goeppingeri & 27 & 11 & 5.67 & $0.84 \pm 0.06$ & $2.36 \pm 1.17$ \\
\hline \multicolumn{6}{|l|}{ O. obtusangulus } \\
\hline$N A$ & 20 & 10 & 6.35 & $0.91 \pm 0.04$ & $1.70 \pm 0.86$ \\
\hline$S A$ & 19 & 8 & 5.22 & $0.84 \pm 0.06$ & $2.20 \pm 1.11$ \\
\hline Combined & 39 & 18 & 7.12 & $0.94 \pm 0.02$ & $3.05 \pm 1.49$ \\
\hline O. venezuelensis & 14 & 8 & 6.30 & $0.91 \pm 0.05$ & $2.23 \pm 1.15$ \\
\hline
\end{tabular}


Table 2. Pairwise $F_{S T}$ values amongst species calculated from ITS and cpDNA (trnL-F, trnH$p s b \mathrm{~A}$ and $r p / 32-t r n \mathrm{~L}$ ) considering $O$. obtusangulus as (a) one species and (b) as two species. Values for ITS are below the diagonal and cpDNA above. Bold numbers denote significance at the $5 \%$ level. cle: $O$. cleefii, ecu: $O$. ecuadorensis, goe: $O$. goeppingeri, obt: $O$. obtusangulus and ven: $O$. venezuelensis.

(a)

\begin{tabular}{|c|c|c|c|c|c|c|}
\hline \multirow[b]{2}{*}{ cle } & cle & ecu & goe & obt & ven & \multirow[b]{2}{*}{ cle } \\
\hline & & 0.797 & 0.283 & 0.098 & 0.317 & \\
\hline u & 0.770 & & 0.732 & 0.600 & 0.801 & ect \\
\hline yoe & 0.284 & 0.307 & & 0.229 & 0.288 & goc \\
\hline obt & 0.269 & 0.360 & 0.289 & & 0.256 & $o b$ \\
\hline en & 0.314 & 0.328 & 0.175 & 0.291 & & ver \\
\hline & cle & ecu & goe & obt & ven & \\
\hline
\end{tabular}

(b)

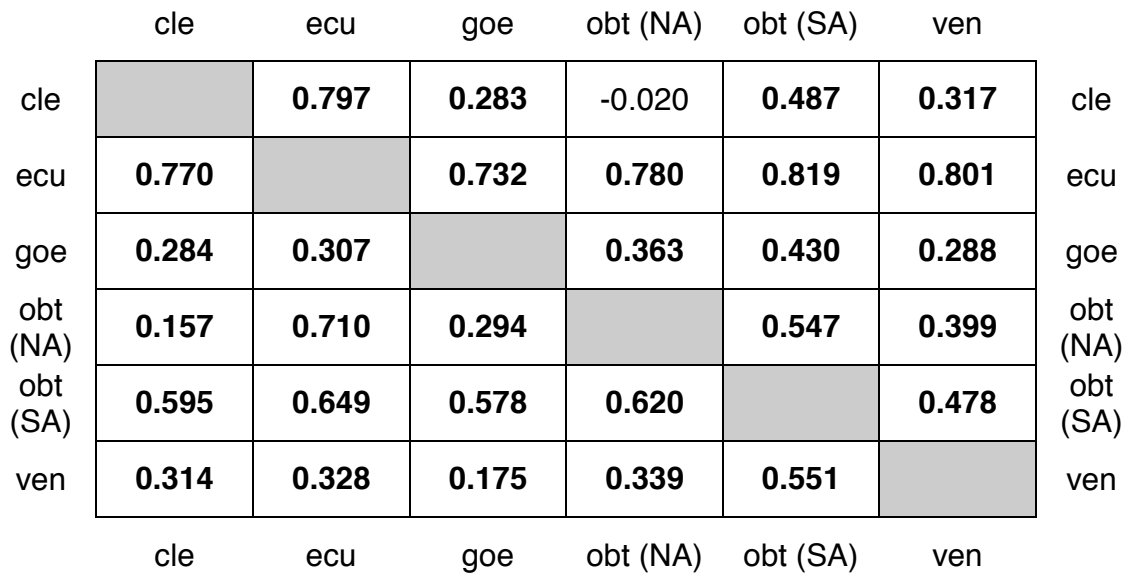


Table 3. Analysis of molecular variance (AMOVA) results for ITS and cpDNA (trnL-F, trnH-psbA and $r p / 32-t r n \mathrm{~L})$.

\begin{tabular}{|c|c|c|c|c|c|c|c|c|c|c|c|}
\hline \multirow{2}{*}{ Group level } & \multirow{2}{*}{ Source of variation } & \multicolumn{2}{|c|}{ Degrees of freedom } & \multicolumn{2}{|c|}{ Sum of Squares } & \multicolumn{2}{|c|}{$\begin{array}{l}\text { Variance } \\
\text { components }\end{array}$} & \multicolumn{2}{|c|}{$\begin{array}{l}\text { Percentage of } \\
\text { variation }\end{array}$} & \multicolumn{2}{|c|}{ Fixation indices } \\
\hline & & ITS & cpDNA & ITS & cpDNA & ITS & cpDNA & ITS & cpDNA & ITS & cpDNA \\
\hline \multirow[t]{2}{*}{ Species } & Among species & 4 & 4 & 260 & 2033 & 1.69 & 21.67 & 30.46 & 47.65 & $F_{S T}=0.31^{\star \star \star}$ & $\mathrm{F}_{\mathrm{ST}}=0.48^{\star \star \star}$ \\
\hline & Within species & 192 & 113 & 741 & 2689 & 3.86 & 23.80 & 69.54 & 52.35 & & \\
\hline \multirow{2}{*}{$\begin{array}{l}\text { Clusters (all } \\
\text { clusters) }\end{array}$} & Among clusters & 13 & 12 & 442 & 1925 & 2.30 & 15.54 & 42.95 & 36.84 & $F_{S T}=0.43^{\star \star \star}$ & $F_{S T}=0.37^{\star \star \star}$ \\
\hline & Within clusters & 183 & 105 & 560 & 2798 & 3.06 & 26.65 & 57.05 & 63.16 & & \\
\hline \multirow{2}{*}{$\begin{array}{l}\text { Clusters (northern } \\
\text { Andes - NA) }\end{array}$} & Among clusters & 9 & 8 & 88 & 885 & 0.46 & 7.88 & 14.50 & 21.34 & $\mathrm{~F}_{\mathrm{ST}}=0.15^{\star \star}$ & $F_{S T}=0.21^{* * *}$ \\
\hline & Within clusters & 154 & 90 & 416 & 2612 & 2.70 & 29.03 & 85.50 & 78.66 & & \\
\hline \multirow{3}{*}{$\begin{array}{l}\text { Continental regions } \\
\text { (NA vs SA) }\end{array}$} & Among regions & 1 & 1 & 309 & 746 & 5.38 & 19.89 & 59.49 & 35.54 & $\mathrm{~F}_{\mathrm{CT}}=0.60^{* * *}$ & $F_{\mathrm{CT}}=0.36^{\star \star \star}$ \\
\hline & $\begin{array}{l}\text { Among clusters within } \\
\text { regions }\end{array}$ & 12 & 11 & 133 & 1179 & 0.61 & 9.41 & 6.72 & 16.82 & $\mathrm{FSC}_{\mathrm{SC}}=0.17^{\star \star}$ & $F_{S C}=0.26^{\star * *}$ \\
\hline & Within clusters & 183 & 105 & 560 & 2798 & 3.06 & 26.65 & 33.79 & 47.64 & $F_{S T}=0.66^{\star \star \star}$ & FST $=0.52^{\star \star \star}$ \\
\hline \multirow[t]{3}{*}{ SAMOVA groups } & Among groups & 2 & 2 & 348 & 999 & 5.71 & 25.47 & 62.19 & 42.59 & $\mathrm{~F}_{\mathrm{CT}}=0.62^{\star \star \star}$ & $F_{C T}=0.43^{\star \star \star}$ \\
\hline & $\begin{array}{l}\text { Among clusters within } \\
\text { groups }\end{array}$ & 11 & 10 & 93 & 926 & 0.41 & 7.68 & 4.51 & 12.84 & $F_{s C}=0.12^{*}$ & $F_{S C}=0.22^{\star \star \star}$ \\
\hline & Within clusters & 183 & 105 & 560 & 2798 & 3.06 & 26.65 & 33.30 & 44.56 & $\mathrm{FST}_{\mathrm{ST}}=0.67^{\star \star \star}$ & $F_{S T}=0.55^{\star \star \star}$ \\
\hline
\end{tabular}


Table 4. Molecular diversity indices for ITS and cpDNA (trnL-F, trnH-psbA and rp/32-trnL) for each SAMOVA grouping. $\mathrm{N}$ : number of individuals; $\mathrm{H}$ : number of haplotypes; hr: haplotype richness (ITS, rarefied to a minimum sample of 16; cpDNA, rarefied to a minimum sample of 9 ); h, haplotype diversity ( $\pm S D) ; \pi$, nucleotide diversity $( \pm S D)$.

\begin{tabular}{lccccc}
\hline SAMOVA group & $\mathrm{N}$ & $\mathrm{H}$ & $\mathrm{hr}$ & $\mathrm{h}$ & $\mathrm{T} \times 100$ \\
\hline I & ITS & & & & \\
II & 164 & 25 & 9.20 & $0.91 \pm 0.01$ & $1.18 \pm 0.63$ \\
III & 17 & 5 & 4.88 & $0.58 \pm 0.13$ & $2.18 \pm 1.17$ \\
& 16 & 2 & 2.00 & $0.13 \pm 0.11$ & $1.46 \pm 0.80$ \\
I & $c P D N A$ & & & & \\
II & 100 & 33 & 7.43 & $0.95 \pm 0.01$ & $3.03 \pm 1.46$ \\
III & 9 & 4 & 4.00 & $0.58 \pm 0.18$ & $1.90 \pm 1.04$ \\
\hline
\end{tabular}




\section{FIGURES}

770 Fig. 1 Geographical distribution of Oreobolus in South America based on herbarium

771 records (coloured dots). Sampling localities $(1-32)$ and their corresponding cluster

$772(\mathrm{~A}-\mathrm{N})$ are also indicated. Arrows denote geographical features.

773 Fig. 2 Maximum clade credibility tree from the *BEAST 2 analysis based on ITS

774 and cpDNA (trnL-F, trnH-psbA and rpl32-trnL). Numbers above the branches

775 represent posterior probability values. Node bars show 95\% HPD. NAC, northern

776 Andean clade.

777 Fig. 3 NeighborNet network for the ITS haplotypes based on the uncorrected-p

778 distances. Haplotypes are coloured according to species. Shared haplotypes are

779 shown in white, with pie charts below (labelled with haplotype number) showing the

780 frequency per species. NA: northern Andes, SA: southern Andes

781 Fig. 4 NeighborNet network for the cpDNA (trnL-F, $\operatorname{trnH}-p s b \mathrm{~A}$ and $r p l 32-\operatorname{trn} \mathrm{L}$ )

782 haplotypes based on the uncorrected-p distances. Haplotypes are coloured according

783 to species. Shared haplotypes are shown in white, with pie charts (labelled with

784 haplotype number) indicating frequency per species shown below. NA: northern

785 Andes, SA: southern Andes

786 Fig. 5 NeighborNet network showing genetic relatedness amongst clusters based on

787 ITS and cpDNA (trnL-F, trnH-psbA and $r p l 32-t r n \mathrm{~L})$ FST pairwise values. 
Supplementary Table 1. Geographic coordinates and corresponding cluster of the sampling localities.

\begin{tabular}{|c|c|c|c|c|}
\hline $\mathrm{N}^{\circ}$ & SAMPLING LOCALITY & CLUSTER & LATITUDE & LONGITUDE \\
\hline 1 & CHIRRIPO & A & 9.48411000 & -83.48861000 \\
\hline 2 & COCUY & B & 6.41211667 & -72.33128333 \\
\hline 3 & LA RUSIA & C & 5.93951667 & -73.07583333 \\
\hline 4 & IGUAQUE & C & 5.68610000 & -73.44773333 \\
\hline 5 & TOTA-BIJAGUAL & B & 5.48143333 & -72.85540000 \\
\hline 6 & RABANAL & C & 5.40818333 & -73.54915000 \\
\hline 7 & GUERRERO & C & 5.22618333 & -74.01788333 \\
\hline 8 & CHINGAZA & $\mathrm{D}$ & 4.52848333 & -73.75866667 \\
\hline 9 & SUMAPAZ & $\mathrm{D}$ & 4.28958333 & -74.20781667 \\
\hline 10 & PURACE & $\mathrm{E}$ & 2.36088333 & -76.35038333 \\
\hline 11 & AZUFRAL & $\mathrm{F}$ & 1.09543333 & -77.68711667 \\
\hline 12 & VOLCAN CHILES & $\mathrm{F}$ & 0.80000000 & -77.93333333 \\
\hline 13 & MIRADOR & $\mathrm{F}$ & 0.56666667 & -77.65000000 \\
\hline 14 & СОTOCACHI & $\mathrm{F}$ & 0.36666667 & -78.33333333 \\
\hline 15 & СOTOPAXI & G & -0.66666667 & -78.36666667 \\
\hline 16 & LLANGANATI & G & -1.15000000 & -78.30000000 \\
\hline 17 & ALAO-HUAMBOYA & G & -1.80000000 & -78.43333333 \\
\hline 18 & PARAMO DE LAS CAJAS & $\mathrm{H}$ & -2.81666667 & -79.26666667 \\
\hline 19 & CUENCA-LIMON & $\mathrm{H}$ & -3.00000000 & -78.66666667 \\
\hline 20 & CUENCA-LOJA & $\mathrm{H}$ & -3.16666667 & -79.03333333 \\
\hline 21 & PODOCARPUS & 1 & -4.40000000 & -79.10000000 \\
\hline 22 & CAJAMARCA & $\mathrm{J}$ & -7.05000000 & -78.58333333 \\
\hline 23 & HUASCARAN & $\mathrm{J}$ & -9.45000000 & -77.26666000 \\
\hline 24 & VALDIVIA & $\mathrm{K}$ & -40.18333333 & -73.51666666 \\
\hline 25 & FIORDO PEEL & L & -50.50000000 & -73.73333333 \\
\hline 26 & MALVINAS & N & -51.64297000 & -59.89473000 \\
\hline 27 & MORRO PHILIPPI & L & -51.73333333 & -71.50000000 \\
\hline 28 & MAGALLANES & L & -53.45000000 & -71.76666700 \\
\hline 29 & TIERRA DEL FUEGO & M & -54.76666666 & -67.40000000 \\
\hline 30 & ISLA DE LOS ESTADOS & M & -54.80000000 & -64.31666666 \\
\hline 31 & ISLA NAVARINO & M & -55.07553100 & -67.65539600 \\
\hline 32 & CABO DE HORNOS & $M$ & -55.94407800 & -67.28092500 \\
\hline
\end{tabular}


Supplementary Table 2. Sequence information

Supplementary Table 3. Number of individuals successfully sequenced per species per sampling locality for ITS and cpDNA (trnL-F, trnH-psbA and rp/32-trnL). Areas where species are not distributed are noted as n.d.

\begin{tabular}{|c|c|c|c|c|c|c|c|c|c|c|}
\hline \multirow{2}{*}{ CLUSTER/Sampling locality } & \multicolumn{2}{|c|}{ O. cleefii } & \multicolumn{2}{|c|}{ O. ecuadorensis } & \multicolumn{2}{|c|}{ O. goeppingeri } & \multicolumn{2}{|c|}{ O. obtusangulus } & \multicolumn{2}{|c|}{ O. venezuelensis } \\
\hline & ITS & cpDNA & ITS & cpDNA & ITS & cpDNA & ITS & cpDNA & ITS & cpDNA \\
\hline \multicolumn{11}{|l|}{ CLUSTER A } \\
\hline (1) Chirripo & n.d. & n.d. & n.d. & n.d. & 2 & - & n.d. & n.d. & - & - \\
\hline \multicolumn{11}{|l|}{ CLUSTER B } \\
\hline (2) Cocuy & 5 & 4 & n.d. & n.d. & 3 & 4 & - & - & - & - \\
\hline (5) Tota-Bijagual & 2 & 1 & n.d. & n.d. & 2 & 1 & - & - & - & - \\
\hline \multicolumn{11}{|l|}{ CLUSTER C } \\
\hline (4) Iguaque & - & - & n.d. & n.d. & 1 & 1 & - & - & - & - \\
\hline (3) La Rusia & 2 & 2 & n.d. & n.d. & 1 & - & - & - & 2 & 1 \\
\hline (6) Rabanal & - & - & n.d. & n.d. & 2 & 1 & - & - & - & - \\
\hline (7) Guerrero & 1 & - & n.d. & n.d. & 1 & - & - & - & - & - \\
\hline \multicolumn{11}{|l|}{ CLUSTER D } \\
\hline (8) Chingaza & 1 & - & n.d. & n.d. & 3 & 1 & - & - & 2 & 1 \\
\hline (9) Sumapaz & - & - & n.d. & n.d. & 3 & 2 & 1 & - & 4 & 2 \\
\hline \multicolumn{11}{|l|}{ CLUSTER E } \\
\hline (10) Purace & n.d. & n.d. & n.d. & n.d. & 3 & 3 & - & - & - & - \\
\hline \multicolumn{11}{|l|}{ CLUSTER F } \\
\hline (11) Azufral & 4 & 2 & - & - & 1 & 1 & - & - & - & - \\
\hline (12) Volcan Chiles & - & - & 1 & 1 & 5 & - & 5 & 4 & - & - \\
\hline (13) Mirador & - & - & - & - & 2 & 2 & 1 & 2 & 1 & 1 \\
\hline (14) Cotocachi & n.d. & n.d. & 1 & 2 & 3 & 2 & - & - & - & - \\
\hline \multicolumn{11}{|l|}{ CLUSTER G } \\
\hline (15) Cotopaxi & n.d. & n.d. & 9 & 13 & 2 & - & 2 & 2 & - & 1 \\
\hline (16) Llanganati & n.d. & n.d. & - & 1 & 2 & - & 2 & 1 & - & - \\
\hline
\end{tabular}


(17) Alao-Huamboya CLUSTER H

(18) Paramo De Las Cajas

(19) Cuenca-Limon

(20) Cuenca-Loja

CLUSTER I

(21) Podocarpus

CLUSTER J

(22) Cajamarca

(23) Huascaran

CLUSTER K

(24) Valdivia

CLUSTER L

(25) Fiordo Peel

(27) Morro Philippi

(28) Magallanes

CLUSTER M

(29) Tierra Del Fuego

(30) Isla De Los Estados

(31) Isla Navarino

(32) Cabo De Hornos

CLUSTER N

(26) Malvinas n.d.

n.d.

3

2

3

n.d. n.d. 3

n.d. n.d.

n.d. n.d.

n.d. n.d.

n.d. n.d.

n.d. n.d

n.d.

n.d.

n.d.

n.d.

n.d. n.d.

n.d. n.d.

n.d.

n.d.

n.d.

n.d.

n.d.

n.d.

n.d.

n.d.

n.d.

n.d.

n.d.

n.d.

n.d.

n.d.

n.d.

n.d.

27
56 
Supplementary Table 4. Frequency of occurrence of ITS haplotypes $(\mathrm{Hn})$ across clusters and species. Clusters $(A-N)$ as described in Figure 1 and Supplementary Table 1. cle: $O$. cleefii, ecu: $O$. ecuadorensis, goe: $O$. goeppingeri, obt: $O$. obtusangulus and ven: $O$. venezuelensis.

\begin{tabular}{|c|c|c|c|c|c|c|c|c|c|c|c|c|c|c|c|}
\hline & & \multicolumn{10}{|c|}{ NORTHERN ANDES } & \multicolumn{4}{|c|}{$\begin{array}{c}\text { SOUTHERN } \\
\text { ANDES }\end{array}$} \\
\hline & & $A$ & $\mathrm{~B}$ & $\mathrm{C}$ & $\mathrm{D}$ & $E$ & $\mathrm{~F}$ & $\mathrm{G}$ & $\mathrm{H}$ & l & $J$ & $\mathrm{~K}$ & $\mathrm{~L}$ & $\mathrm{M}$ & $\mathrm{N}$ \\
\hline \multirow{5}{*}{$\mathrm{Hn} 1$} & cle & . & . & . & 1 & . & . & . & . & . & . & . & . & . & . \\
\hline & ecu & . & . & . & . & . & . & . & . & . & . & . & . & . & . \\
\hline & goe & . & . & . & . & . & . & . & . & . & . & . & . & . & . \\
\hline & $o b t$ & . & . & . & . & . & . & . & . & . & . & . & . & . & . \\
\hline & ven & . & . & . & . & . & . & . & . & . & . & . & . & . & . \\
\hline \multirow{5}{*}{$\mathrm{Hn} 2$} & cle & . & 7 & 1 & . & . & . & . & . & . & . & . & . & . & . \\
\hline & ecu & . & . & . & . & . & . & . & . & . & . & . & . & . & . \\
\hline & goe & . & . & . & . & . & . & . & . & . & . & . & . & . & . \\
\hline & $o b t$ & . & . & . & 1 & . & . & . & . & . & . & . & . & . & . \\
\hline & ven & . & . & . & . & . & . & . & . & . & . & . & . & . & . \\
\hline \multirow{5}{*}{ Hn3 } & cle & . & . & 2 & . & . & . & . & $\cdot$ & . & . & . & . & . & . \\
\hline & ecu & . & . & . & . & . & 2 & 11 & 8 & . & . & . & . & . & . \\
\hline & goe & . & . & . & . & . & . & . & . & . & . & . & . & . & . \\
\hline & $o b t$ & . & . & . & . & . & . & . & . & 1 & . & . & . & . & . \\
\hline & ven & . & . & . & . & . & . & . & . & . & . & . & . & . & . \\
\hline \multirow{5}{*}{$\mathrm{Hn} 4$} & cle & . & . & . & . & . & 3 & . & . & . & . & . & . & . & . \\
\hline & ecu & . & . & . & . & . & . & . & . & . & . & . & . & . & . \\
\hline & goe & . & . & . & . & . & 2 & 3 & . & 1 & . & . & . & . & . \\
\hline & $o b t$ & . & . & . & . & . & 1 & . & . & . & . & . & . & . & . \\
\hline & ven & . & . & . & . & . & . & . & . & . & . & . & . & . & . \\
\hline \multirow{5}{*}{$\mathrm{Hn} 5$} & cle & . & . & . & . & . & 1 & . & . & . & . & . & . & . & . \\
\hline & ecu & . & . & . & . & . & . & . & . & . & . & . & . & . & . \\
\hline & goe & . & . & . & . & . & . & . & . & . & . & . & . & . & . \\
\hline & $o b t$ & . & . & . & . & . & 2 & 1 & . & . & . & . & . & . & . \\
\hline & ven & . & . & . & . & . & . & . & . & . & . & . & . & . & . \\
\hline \multirow{5}{*}{$\mathrm{Hn} 6$} & cle & . & . & . & . & . & . & . & . & . & . & . & . & . & . \\
\hline & ecu & . & . & . & . & . & . & 1 & . & . & . & . & . & . & . \\
\hline & goe & . & . & . & . & . & . & . & . & . & . & . & . & . & . \\
\hline & $o b t$ & . & . & . & . & . & . & . & . & . & . & . & . & . & . \\
\hline & ven & . & . & . & . & . & . & . & . & . & . & . & . & . & . \\
\hline \multirow{5}{*}{$\mathrm{Hn} 7$} & cle & . & . & . & . & . & . & . & . & . & . & . & . & . & . \\
\hline & ecu & . & . & . & . & . & . & . & . & . & 2 & . & . & . & . \\
\hline & goe & . & . & . & . & . & . & . & . & . & . & . & . & . & . \\
\hline & $o b t$ & . & . & . & . & . & . & . & . & . & . & . & . & . & . \\
\hline & ven & . & . & . & . & . & . & . & . & . & . & . & . & . & . \\
\hline \multirow{5}{*}{ Hn8 } & cle & . & . & . & . & . & . & . & . & . & . & . & . & . & . \\
\hline & ecu & . & . & . & . & . & . & . & . & . & 1 & . & . & . & . \\
\hline & goe & . & . & . & . & . & . & . & . & . & . & . & . & . & . \\
\hline & $o b t$ & . & . & . & . & . & . & . & . & . & 1 & . & . & . & . \\
\hline & ven & . & . & . & . & . & . & . & . & . & . & . & . & . & . \\
\hline \multirow{5}{*}{ Hn9 } & cle & . & . & . & . & . & . & . & . & . & . & . & . & . & . \\
\hline & ecu & . & . & . & . & . & . & . & . & . & . & . & . & . & . \\
\hline & goe & . & . & . & . & 2 & 6 & 3 & 5 & 13 & . & . & . & . & . \\
\hline & $o b t$ & . & . & . & . & . & . & . & 1 & . & . & . & . & . & . \\
\hline & ven & . & . & . & . & . & . & . & . & . & . & . & . & . & . \\
\hline \multirow{5}{*}{ Hn10 } & cle & . & . & . & . & . & . & . & . & . & . & . & . & . & . \\
\hline & ecu & . & . & . & . & $\cdot$ & . & . & . & . & . & . & . & . & . \\
\hline & goe & . & 1 & 1 & 3 & 1 & . & . & . & . & . & . & . & . & . \\
\hline & $o b t$ & . & . & . & . & . & . & 1 & . & . & . & . & . & . & . \\
\hline & ven & . & 1 & 1 & 2 & . & 1 & . & . & . & . & . & . & . & . \\
\hline Hn11 & cle & . & . & . & . & . & . & . & . & & . & . & . & . & . \\
\hline
\end{tabular}




\begin{tabular}{|c|c|c|c|c|c|c|c|c|c|c|c|c|c|c|c|}
\hline & ecu & . & i & i & i & . & i & . & i & . & i & . & $\cdot$ & . & . \\
\hline & goe & . & 2 & 4 & 3 & . & 3 & . & 3 & $\cdot$ & 1 & $\cdot$ & . & $\cdot$ & $\cdot$ \\
\hline & $o b t$ & $\cdot$ & . & . & . & . & . & . & . & . & . & $\cdot$ & . & . & . \\
\hline & ven & . &. & . & . & . & . & . & . & . & . & . &. &. & . \\
\hline \multirow{5}{*}{ Hn12 } & cle & . & . & . & . & . & . & . & . & . & . & . & . & . & . \\
\hline & ecu & . & $\cdot$ & . & . & . & . & . & $\cdot$ & . & . & . & . & . & . \\
\hline & goe & . & $\cdot$ & . & . & . & . & . & 7 & 2 & . & . & . & . & . \\
\hline & $o b t$ & . & $\cdot$ & . & $\cdot$ & . & . & . & $\cdot$ & . & . & . & $\cdot$ & . & . \\
\hline & ven & . &. & . & . & . & . & . &. & . &. & . &. &. & . \\
\hline \multirow{5}{*}{ Hn13 } & cle & . & $\cdot$ & . & . & . & . & . & . & . & . & . & . & . & . \\
\hline & ecu & . & $\cdot$ & . & . & . & . & . & $\cdot$ & . & . & . & . & . & . \\
\hline & goe & . & $\cdot$ & . & . & . & . & . & $\cdot$ & 1 & . & . & . & . & . \\
\hline & $o b t$ & $\cdot$ & $\cdot$ & $\cdot$ & $\cdot$ & . & $\cdot$ & . & $\cdot$ & $\cdot$ & $\cdot$ & - & $\cdot$ & $\cdot$ & . \\
\hline & ven & . & . & . & . & . & . & . &. & . & . & . & . & . & . \\
\hline \multirow{5}{*}{ Hn14 } & cle & . & $\cdot$ & . & . & . & . & . & . & . & . & · & . & . & . \\
\hline & $e c u$ & . & $\cdot$ & . & . & . & . & . & $\cdot$ & . & . & . & $\cdot$ & . & . \\
\hline & goe & . & . & . & . & . & . & . & . & 1 & . & . & . & . & . \\
\hline & $o b t$ & . & . & . & . & . & . & . & . & . & . & . & . & . & . \\
\hline & ven & . & . & . & . & . & . & . &. &. & . & . &. &. & . \\
\hline \multirow{5}{*}{ Hn15 } & cle & $\cdot$ & $\cdot$ & . & $\cdot$ & - & . & $\cdot$ & . & . & . & - & $\cdot$ & $\cdot$ & . \\
\hline & $e c u$ & . & $\cdot$ & $\cdot$ & $\cdot$ & . & . & . & $\cdot$ & $\cdot$ & $\cdot$ & . & $\cdot$ & $\cdot$ & . \\
\hline & goe & . & $\cdot$ & $\cdot$ & $\cdot$ & . & . & 1 & $\cdot$ & . & . & . & . & $\cdot$ & . \\
\hline & $o b t$ & . & $\cdot$ & . & . & . & . & . & $\cdot$ & . & . & . & . & . & . \\
\hline & ven & . & . & . &. & . & . & . & . & . & . & . &. & . & . \\
\hline \multirow{5}{*}{ Hn16 } & cle & . & . & . & . & . & . & $\cdot$ & $\cdot$ & . & . & . & . & . & . \\
\hline & $e c u$ & . & . & . & . & . & . & . & . & . & . & . & . & . & . \\
\hline & goe & . & 2 & . & . & . & . & . & . & . & . & . & . & . & . \\
\hline & $o b t$ & . & . & . & . & . & . & . & . & . & . & . & . & . & . \\
\hline & ven & . & . & . & 2 & . & . & . & . & . & . & . & . & . & . \\
\hline \multirow{5}{*}{ Hn17 } & cle & - & $\cdot$ & $\cdot$ & $\cdot$ & $\cdot$ & $\cdot$ & . & . & $\cdot$ & $\cdot$ & $\cdot$ & $\cdot$ & . & . \\
\hline & ecu & . & . & . & . & . & . & . & $\cdot$ & . & . & . & . & . & . \\
\hline & goe & . & . & . & . & . & . & . & . & . & 1 & - & . & . & . \\
\hline & $o b t$ & . & $\cdot$ & $\cdot$ & $\cdot$ & $\cdot$ & $\cdot$ & $\cdot$ & $\cdot$ & . & $\cdot$ & $\cdot$ & · & · & . \\
\hline & ven & . & . & . &. & . & . & . & . & . & . & . &. &. & . \\
\hline \multirow{5}{*}{ Hn18 } & cle & $\cdot$ & $\cdot$ & $\cdot$ & $\cdot$ & - & $\cdot$ & $\cdot$ & $\cdot$ & $\cdot$ & $\cdot$ & - & $\cdot$ & $\cdot$ & . \\
\hline & $e c u$ & . & $\cdot$ & . & . & . & . & . & $\cdot$ & . & . & . & . & . & . \\
\hline & goe & . & $\cdot$ & . & . & . & . & . & $\cdot$ & . & 1 & . & . & . & . \\
\hline & $o b t$ & . & . & . & . & . & . & . & $\cdot$ & . & . & . & . & . & . \\
\hline & ven & . & . & . &. & . & . & . & . & . & . & . &. &. & . \\
\hline \multirow{5}{*}{ Hn19 } & cle & · & $\cdot$ & $\cdot$ & $\cdot$ & - & . & $\cdot$ & $\cdot$ & $\cdot$ & $\cdot$ & - & $\cdot$ & $\cdot$ & . \\
\hline & $e c u$ & . & . & . & . & . & . & . & . & . & . & . & . & . & . \\
\hline & goe & 2 & . & . & . & . & . & . & . & . & $\cdot$ & . & . & . & . \\
\hline & $o b t$ & $\cdot$ & $\cdot$ & $\cdot$ & $\cdot$ & . & $\cdot$ & $\cdot$ & $\cdot$ & $\cdot$ & $\cdot$ & . & $\cdot$ & . & . \\
\hline & ven & . & . & . & . & . & . &. & . & . & . & . & . & . & . \\
\hline \multirow{5}{*}{$\mathrm{Hn} 20$} & cle & · & . & $\cdot$ & $\cdot$ & $\cdot$ & $\cdot$ & · & . & $\cdot$ & . & $\cdot$ & $\cdot$ & · & . \\
\hline & ecu & . & . & . & . & . & . & . & . & . & . & . & . & . & . \\
\hline & goe & . & . & . & . & . & . & . & . & . & . & . & . & . & . \\
\hline & $o b t$ & . & . & . & . & . & . & . & . & . & . & . & 10 & . & 1 \\
\hline & ven & . & . & . & . & . & . & . & . & . & . & . & $\cdot$ & . & . \\
\hline \multirow{5}{*}{$\mathrm{Hn} 21$} & cle & - & $\cdot$ & . & $\cdot$ & - & $\cdot$ & $\cdot$ & $\cdot$ & $\cdot$ & $\cdot$ & . & $\cdot$ & $\cdot$ & . \\
\hline & $e c u$ & . & . & . & . & . & . & . & . & . & . & . & . & . & . \\
\hline & goe & . & . & . & $\cdot$ & . & . & . & $\cdot$ & . & . & . & . & . & . \\
\hline & $o b t$ & . & . & . & $\cdot$ & . & . & . & $\cdot$ & . & . & . & 1 & 1 & . \\
\hline & ven & . & . &. &. & . & . & . &. & . &. & . &. &. & . \\
\hline \multirow{5}{*}{ Hn22 } & cle & . & . & . & $\cdot$ & . & . & $\cdot$ & $\cdot$ & . & . & - & . & . & . \\
\hline & ecu & . & . & . & . & . & . & $\cdot$ & . & . & . & . & . & . & . \\
\hline & goe & . & . & . & . & . & . & . & . & . & . & . & i & . & . \\
\hline & $o b t$ & . & . & . & . & . & . & . & . & . & . & . & 2 & 15 & . \\
\hline & ven & . & . & . & . & . & . & . & . & . & . & . & . & . & . \\
\hline Hn23 & cle & 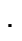 & $\cdot$ & $\cdot$ & $\cdot$ & . & $\cdot$ & $\cdot$ & $\cdot$ & . & . & . & . & . & \\
\hline
\end{tabular}




\begin{tabular}{|c|c|c|c|c|c|c|c|c|c|c|c|c|c|c|c|}
\hline & ecu & . & . & . & $\cdot$ & $\cdot$ & . & . & . & . & . & . & . & . & . \\
\hline & goe & . & . & . & . & . & . & . & . & . & . & . & . & . & . \\
\hline & $o b t$ & . & . & . & . & . & . & . & . & . & . & 1 & . & . & . \\
\hline & ven &. & . & . & . & . &. & . & . &. & . &. &. & . & . \\
\hline \multirow{5}{*}{ Hn24 } & cle & . & . & . & . & . & . & . & . & . & . & . & . & . & . \\
\hline & $e c u$ & $\cdot$ & . & . & . & . & . & . & . & . & . & . & . & . & . \\
\hline & goe & . & . & . & . & . & . & . & . & . & . & . & . & . & . \\
\hline & $o b t$ & . & . & . & . & . & 3 & 2 & 8 & . & . & . & . & . & . \\
\hline & ven &. & . & . & . & . &. & . & . & . & . & . & . & . & . \\
\hline \multirow{5}{*}{ Hn25 } & cle & . & . & . & . & $\cdot$ & . & . & $\cdot$ & $\cdot$ & $\cdot$ & . &. & . & . \\
\hline & ecu & . & . & . & . & . & . & . & . & . & . & . & . & . & . \\
\hline & goe & . & . & . & $\cdot$ & $\cdot$ & . & . & . & . & . & . & . & . & . \\
\hline & $o b t$ & . & . & . & . & . & . & . & . & . & . & . & 2 & . & . \\
\hline & ven & . & . & . & . & . & . & . & . & . & . & . & . & . & . \\
\hline \multirow{5}{*}{ Hn26 } & cle & . & . & . & . & $\cdot$ &. & . & . & . & . & . & . & . & . \\
\hline & $e c u$ & . & . & . & . & . & . & . & . & $\cdot$ & . & . & . & . & . \\
\hline & goe & . & . & . & $\cdot$ & . & . & . & . & . & . & $\cdot$ & . & . & . \\
\hline & $o b t$ & . & . & . & $\cdot$ & $\cdot$ & . & . & . & . & . & $\cdot$ & . & - & . \\
\hline & ven & . & . & 1 & . & . &. & . & . &. & . & . &. & . & . \\
\hline \multirow{5}{*}{ Hn27 } & cle & $\cdot$ & $\cdot$ & $\cdot$ & $\cdot$ & $\cdot$ & $\cdot$ & $\cdot$ & $\cdot$ & $\cdot$ & . & $\cdot$ & $\cdot$ & · & . \\
\hline & $e c u$ & $\cdot$ & . & . & . & . & $\cdot$ & . & $\cdot$ & $\cdot$ & . & . & $\cdot$ & . & . \\
\hline & goe & . & . & . & . & . & . & . & . & $\cdot$ & . & . & . & . & . \\
\hline & $o b t$ & . & . & . & . & . & $\cdot$ & . & . & $\cdot$ & . & . & . & . & . \\
\hline & ven &. & . & . & 1 & . &. & . & . & . & . & . &. & . & . \\
\hline \multirow{5}{*}{ Hn28 } & cle & $\cdot$ & . & . & . & $\cdot$ & . & $\cdot$ & $\cdot$ & $\cdot$ & . & $\cdot$ & $\cdot$ & . & . \\
\hline & ecu & . & . & · & $\cdot$ & $\cdot$ & . & . & . & $\cdot$ & $\cdot$ & $\cdot$ & . & . & · \\
\hline & goe & . & . & . & $\cdot$ & $\cdot$ & . & . & . & $\cdot$ & $\cdot$ & $\cdot$ & . & . & . \\
\hline & $o b t$ & $\cdot$ & . & $\cdot$ & . & . & $\cdot$ & . & $\cdot$ & $\cdot$ & . & . & $\cdot$ & . & . \\
\hline & ven & . & . & . & . & . & . & . & 1 & 15 &. & . & . & . & . \\
\hline \multirow{5}{*}{ Hn29 } & cle & $\cdot$ & . & . & . & $\cdot$ & $\cdot$ & . & $\cdot$ & $\cdot$ & . & $\cdot$ & $\cdot$ & · & . \\
\hline & $e c u$ & . & . & . & . & . & . & . & . & $\cdot$ & . & . & . & · & . \\
\hline & goe & . & . & . & . & $\cdot$ & . & . & . & . & . & . & . & . & . \\
\hline & $o b t$ & . & . & . & . & . & . & . & . & . & . & $\cdot$ & . & · & $\cdot$ \\
\hline & ven &. & . & . & 1 & . &. & . & . & . & . & . &. & . & . \\
\hline \multirow{5}{*}{ Hn30 } & cle & $\cdot$ & $\cdot$ & $\cdot$ & $\cdot$ & $\cdot$ & $\cdot$ & $\cdot$ & $\cdot$ & $\cdot$ & . & $\cdot$ & $\cdot$ & - & . \\
\hline & $e c u$ &. & . & . & . & $\cdot$ & . & . & . & $\cdot$ & . & $\cdot$ &. & . & . \\
\hline & goe & . & . & $\cdot$ & $\cdot$ & $\cdot$ & . & . & $\cdot$ & $\cdot$ & . & $\cdot$ & . & · & · \\
\hline & $o b t$ & . & . & . & $\cdot$ & $\cdot$ & . & . & . & $\cdot$ & - & . & . & . & · \\
\hline & ven & . & . & . & . & . & . & . & 1 & . & . & . & . & . & . \\
\hline
\end{tabular}


Supplementary Table 5. Frequency of occurrence of cpDNA (trnL-F, $\operatorname{trnH}-p s b \mathrm{~A}$ and $r p / 32-$ $t r n \mathrm{~L})$ haplotypes $(\mathrm{Hc})$ across clusters and species. Clusters $(\mathrm{B}-\mathrm{N})$ as described in Figure 1 and Supplementary Table 1. cle: $O$. cleefii, ecu: $O$. ecuadorensis, goe: $O$. goeppingeri, obt: $O$. obtusangulus and ven: $O$. venezuelensis.

\begin{tabular}{|c|c|c|c|c|c|c|c|c|c|c|c|c|c|c|}
\hline & & \multicolumn{9}{|c|}{ NORTHERN ANDES } & \multicolumn{4}{|c|}{$\begin{array}{c}\text { SOUTHERN } \\
\text { ANDES }\end{array}$} \\
\hline & & $B$ & $\mathrm{C}$ & D & $E$ & $\mathrm{~F}$ & G & $\mathrm{H}$ & I & $J$ & K & $\mathrm{L}$ & $\mathrm{M}$ & $\mathrm{N}$ \\
\hline \multirow{5}{*}{$\mathrm{Hc} 1$} & cle & . & 2 & . & . & . & . & . & . & . & . & . & . & . \\
\hline & ecu & . & . & . & . & . & . & . & . & . & . & . & . & . \\
\hline & goe & . & . & . & . & . & . & . & . & . & . & . & . & . \\
\hline & $o b t$ & . & . & . & . & . & . & . & . & . & . & . & . & . \\
\hline & ven & . & . & . & . & . & . & . & . & . & . & . & . & . \\
\hline \multirow{5}{*}{$\mathrm{Hc} 2$} & cle & 4 & . & . & . & . &. & . & . & . & . & . & . & . \\
\hline & ecu & . & . & . & . & . & . & . & . & . & . & . & . & . \\
\hline & goe & . & . & . & . & . & . & . & . & . & . & . & . & . \\
\hline & $o b t$ & . & . & . & . & 3 & . & . & . & . & . & . & . & . \\
\hline & ven & . & . & . & . & . & . & . & . & . & . & . & . & . \\
\hline \multirow{5}{*}{ Hc3 } & cle & 1 &. & . &. & . &. & . & . & . & . & . & . & . \\
\hline & ecu & . &. & . & . & . & . & . & . & . & . & . & . & . \\
\hline & goe & . &. & . & . & . & . & . & . & . & . & . & . & . \\
\hline & $o b t$ & . & . & . & . & . & . & . & . & . & . & . & . & . \\
\hline & ven & . & . & . & . & . & . & . & . & . & . & . & . & . \\
\hline \multirow{5}{*}{$\mathrm{Hc} 4$} & cle & . & . & . & . & 2 & . & . & . & . & . & . & . & . \\
\hline & ecu & . & . & . & . & . & . & . & . & . & . & . & . & . \\
\hline & goe & . & . & . & . & . & . & . & 1 & . & . & . & . & . \\
\hline & $o b t$ & . & . & . & . & . & . & . & . & . & . & . & . & . \\
\hline & ven & . &. & . & . & . & . & . & . & . & . & . & . & . \\
\hline \multirow{5}{*}{ Hc5 } & cle & . &. & . &. & . & . & . & . & . & . & . & . & . \\
\hline & ecu & . &. & . & . & 3 & 9 & . & . & . & . & . & . & . \\
\hline & goe & . & . & . & . & . & . & . & . & . & . & . & . & . \\
\hline & $o b t$ & . & . & . & . & . & . & . & . & . & . & . & . & . \\
\hline & ven & . & . & . & . & . & . & . & . & . & . & . & . & . \\
\hline \multirow{5}{*}{ Hc6 } & cle & . &. & . &. & . & . & . & . & . & . & . & . & . \\
\hline & ecu & . & . & . & . & . & 2 & 5 & . & 1 & . & . & . & . \\
\hline & goe & . & . & . & . & . & . & . & . & . & . & . & . & . \\
\hline & $o b t$ & . & . & . & . & . & . & 1 & 1 & 1 & . & . & . & . \\
\hline & ven & . & . & . & . & . & . & . & . & . & . & . & . & . \\
\hline \multirow{5}{*}{$\mathrm{Hc} 7$} & cle & . &. & . & . & . & . & . & . & . & . & . & . & . \\
\hline & ecu & . & . & . & . & . & 4 & 3 & . & . & . & . & . & . \\
\hline & goe & . & . & . & . & . & . & . & . & . & . & . & . & . \\
\hline & $o b t$ & . & . & . & . & . & . & . & . & . & . & . & . & . \\
\hline & ven & . & . & . & . & . & . & . & . & . & . & . & . & . \\
\hline \multirow{5}{*}{ Hc8 } & cle & . &. & . & . & . & . & . & . & . & . & . & . & . \\
\hline & ecu & . & . & . & . & . & 1 & . & . & . & . & . & . & . \\
\hline & goe & . & . & . & . & . & . & . & . & . & . & . & . & . \\
\hline & $o b t$ & . & . & . & . & . & . & . & . & . & . & . & . & . \\
\hline & ven & . & . & . & . & . & . & . & . & . & . & . & . & . \\
\hline \multirow{5}{*}{$\mathrm{Hc} 9$} & cle & . & . & . & . & . & . & . & . & . & . & . & . & . \\
\hline & ecu & . & . & . & . & . & . & . & . & 1 & . & . & . & . \\
\hline & goe & . & . & . & . & . & . & . & . & . & . & . & . & . \\
\hline & $o b t$ & . & . & . & . & . & . & . & . & . & . & . & . & . \\
\hline & ven & . & . & . & . & . & . & . & . & . & . & . & . & . \\
\hline \multirow{5}{*}{ Hc10 } & cle & . & . & . & . & . & . & . & . &. & . & . & . & . \\
\hline & ecu & & . & . & . & . & . & . & . & . & . & . & . & . \\
\hline & goe & . & . & . & . & . & . & . & 1 & ${ }^{\circ}$ & . & . & . & . \\
\hline & $o b t$ & . & . & . & . & . & . & . & . & . & . & . & . & . \\
\hline & ven & . & . & . & . & . & . & . & . & . & . & . & . & . \\
\hline
\end{tabular}




\begin{tabular}{|c|c|c|c|c|c|c|c|c|c|c|c|c|c|c|}
\hline \multirow{5}{*}{$\mathrm{Hc} 11$} & cle & . & . & . & . & . & . & . & . & . & . & . & . & . \\
\hline & ecu & . & . & . & . & . & . & . & . & . & . & . & . & . \\
\hline & goe & . & . & . & . & 2 & . & 2 & . & . & . & . & . & . \\
\hline & $o b t$ & . & . & . & . & . & . & . & . & . & . & . & . & . \\
\hline & ven & . & . & . & . & . & . & . & . & . & . & . & . & . \\
\hline \multirow{5}{*}{$\mathrm{Hc} 12$} & cle & . & . & . & . & . & . & . & . & . & . & . & . & . \\
\hline & ecu & . & . & . & . & . & . & . & . & . & . & . & . & . \\
\hline & goe & 2 & 1 & 2 & . & 2 & . & 3 & . & . & . & . & . & . \\
\hline & $o b t$ & . & . & . & . & . & . & . & . & . & . & . & . & . \\
\hline & ven & . & . & . & . & . & . & . & . & . & . & . & . & . \\
\hline \multirow{5}{*}{$\mathrm{Hc} 13$} & cle & . & . & . & . & . & . & . & . & . & . & . & . & . \\
\hline & ecu & . & . & . & . & . & . & . & . & . & . & . & . & . \\
\hline & goe & 1 & . & 1 & 1 & . & . & . & . & . & . & . & . & . \\
\hline & $o b t$ & . & . & . & . & . & . & . & . & . & . & . & . & . \\
\hline & ven & . & 1 & 2 & . & . & . & . & . & . & . & . & . & . \\
\hline \multirow{5}{*}{$\mathrm{Hc} 14$} & cle & . & . & . & . & . & . & . & . & . & . & . & . & . \\
\hline & ecu & . & . & . & . & . & . & . & . & . & . & . & . & . \\
\hline & goe & 2 & . & . & . & . & . & . & . & . & . & . & . & . \\
\hline & $o b t$ & . & . & . & . & . & . & . & . & . & . & . & . & . \\
\hline & ven & . & . & 1 & . & . & . & . & . & . & . & . & . & . \\
\hline \multirow{5}{*}{$\mathrm{Hc} 15$} & cle & . & . & . & . & . & . & . & . & . & . & . & . & . \\
\hline & ecu & . & . & . & . & . & . & . & . & . & . & . & . & . \\
\hline & goe & . & . & . & 1 & . & . & . & . & . & . & . & . & . \\
\hline & $o b t$ & . & . & . & . & . & . & . & . & . & . & . & . & . \\
\hline & ven & . & . & . & . & . & . & . & . & . & . & . & . & . \\
\hline \multirow{5}{*}{$\mathrm{Hc} 16$} & cle & . & . & . & . & . & . & . & . & . & . & . & . & . \\
\hline & ecu & . & . & . & . & . & . & . & . & . & . & . & . & . \\
\hline & goe & . & . & . & 1 & . & . & . & . & . & . & . & . & . \\
\hline & $o b t$ & . & . & . & . & . & . & . & . & . & . & . & . & . \\
\hline & ven & . & . & . & . & . & . & . & . & . & . & . & . & . \\
\hline \multirow{5}{*}{$\mathrm{Hc} 17$} & cle & . & . & . & . & . & . & . & . & . & . & . & . & . \\
\hline & $e c u$ & . & . & . & . & . & . & . & . & . & . & . & . & . \\
\hline & goe & . & . & . & . & 1 & . & . & . & . & . & . & . & . \\
\hline & $o b t$ & . & . & . & . & . & . & . & . & . & . & . & . & . \\
\hline & ven & . & . & . & . & . & . & . & . & . & . & . & . & . \\
\hline \multirow{5}{*}{$\mathrm{Hc} 18$} & cle & . & . & . & . & . & . & . & . & . & . & . & . & . \\
\hline & ecu & . & . & . & . & . & . & . & . & . & . & . & . & . \\
\hline & goe & . & 1 & . & . & . & . & . & . & . & . & . & . & . \\
\hline & $o b t$ & . & . & . & . & . & . & . & . & . & . & . & . & . \\
\hline & ven & . & . & . & . & . & . & . & . & . & . & . & . & . \\
\hline \multirow{5}{*}{ Hc19 } & cle & . & . & . & . & $\cdot$ & . & . & . & . & . & . & $\cdot$ & . \\
\hline & ecu & . & . & . & . & . & . & . & . & . & . & . & . & . \\
\hline & goe & . & . & . & . & . & . & . & 2 & . & . & . & . & . \\
\hline & $o b t$ & . & . & . & . & . & . & . & . & . & . & . & . & . \\
\hline & ven & . & . & . & . & . & . & . & . & . & . & . & . & . \\
\hline \multirow{5}{*}{ Hc20 } & cle & . & . & . & . & . & . & . & . & . & . & . & . & . \\
\hline & ecu & . & . & . & . & . & . & . & . & . & . & . & . & . \\
\hline & goe & . & . & . & . & . & . & . & . & . & . & . & . & . \\
\hline & $o b t$ & . & . & . & . & . & . & . & . & . & . & 5 & . & 1 \\
\hline & ven & . & . & . & . & . & . & . & . & . & . & . & . & . \\
\hline \multirow{5}{*}{$\mathrm{Hc} 21$} & cle & . & . & . & . & . & . & . & . & . & . & . & . & . \\
\hline & ecu & . & . & . & . & . & . & . & . & . & . & . & . & . \\
\hline & goe & . & . & . & . & . & . & . & . & . & . & . & . & . \\
\hline & $o b t$ & . & . & . & . & . & . & . & . & . & . & 1 & 4 & . \\
\hline & ven & . & . & . & . & . & . & . & . & . & . & . & . & . \\
\hline \multirow{5}{*}{ Hc22 } & cle & . & . & . & . & . & . & . & . & . & . & . & . & . \\
\hline & ecu & . & . & . & . & . & . & . & . & . & . & . & . & . \\
\hline & goe & . & . & . & . & . & . & . & . & . & . & . & . & . \\
\hline & $o b t$ & . & . & . & . & . & . & . & . & . & 1 & . & . & . \\
\hline & ven & . & . & . & . & . & . & . & . & . & . & . & . & . \\
\hline
\end{tabular}




\begin{tabular}{|c|c|c|c|c|c|c|c|c|c|c|c|c|c|c|}
\hline \multirow{5}{*}{ Hc23 } & cle & . & . & . & . & . & . & . & . & . & . & . & $\cdot$ & . \\
\hline & ecu & . & . & . & . & . & . & . & . & . & . & . & . & . \\
\hline & goe & . & . & . & . & . & . & . & . & . & . & . & . & . \\
\hline & $o b t$ & . & . & . & . & . & . & . & . & . & . & . & 1 & . \\
\hline & ven & . & . & . & . & . & . & . & . & . & . & . & . & . \\
\hline \multirow{5}{*}{$\mathrm{Hc} 24$} & cle & . & . & . & . & . & . & . & . & $\cdot$ & . & $\cdot$ & $\cdot$ & . \\
\hline & ecu & . & . & . & . & . & . & . & . & . & . & . & . & . \\
\hline & goe & . & . & . & . & . & . & . & . & . & . & . & . & . \\
\hline & $o b t$ & . & . & . & . & . & 1 & . & . & . & . & . & . & . \\
\hline & ven & . & . & . & . & 1 & . & . & . & . & . & . & . & . \\
\hline \multirow{5}{*}{ Hc25 } & cle & . & $\cdot$ & . & . & . & $\cdot$ & $\cdot$ & $\cdot$ & . & . & · & $\cdot$ & . \\
\hline & ecu & . & . & . & . & . & . & . & . & . & . & . & . & . \\
\hline & goe & . & . & . & . & . & . & . & . & . & . & . & . & . \\
\hline & $o b t$ & . & . & . & . & . & . & 1 & . & . & . & . & . & . \\
\hline & ven & . & . & . & . & . & . & . & . & . & . & . & . & . \\
\hline \multirow{5}{*}{ Hc26 } & cle & . & . & . & . & . & . & . & . & . & . & . & . & . \\
\hline & ecu & . & . & . & . & . & . & . & . & . & . & . & . & . \\
\hline & goe & . & . & . & . & . & . & . & . & $\cdot$ & . & . & . & . \\
\hline & $o b t$ & . & . & . & . & . & . & . & . & . & . & 1 & . & . \\
\hline & ven & . & . & . & . & . & . & . & . & . & . & . &. & . \\
\hline \multirow{5}{*}{$\mathrm{Hc} 27$} & cle & . & . & . & . & . & . & . & $\cdot$ & . & . & . & $\cdot$ & . \\
\hline & ecu & . & . & . & . & . & . & . & . & . & . & . & . & . \\
\hline & goe & . & . & . & . & . & . & . & . & . & . & . & . & . \\
\hline & $o b t$ & . & . & . & . & 1 & 2 & 2 & . & . & . & . & . & . \\
\hline & ven & . & . & . & . & . & . & . & . & . & . & . & . & . \\
\hline \multirow{5}{*}{ Hc28 } & cle & . & . & . & . & . & . & . & . & . & . & . & . & . \\
\hline & ecu & . & . & . & . & . & . & . & . & . & . & . & . & . \\
\hline & goe & . & . & . & . & . & . & . & . & . & . & . & . & . \\
\hline & $o b t$ & . & . & . & . & . & . & 1 & . & . & . & . & . & . \\
\hline & ven & . & . & . & . & . & . & . & . & . & . & . & . & . \\
\hline \multirow{5}{*}{ Hc29 } & cle & . & . & . & . & . & . & . & . & . & . & . & . & . \\
\hline & $e c u$ & . & . & . & . & . & . & . & . & . & . & . & . & . \\
\hline & goe & . & . & . & . & . & . & . & . & . & . & . & . & . \\
\hline & $o b t$ & . & . & . & . & . & . & 1 & . & . & . & . & . & . \\
\hline & ven & . & . & . & . & . & . & . & . & . & . & . & . & . \\
\hline \multirow{5}{*}{ Hc30 } & cle & . & . & . & . & . & $\cdot$ & $\cdot$ & . & $\cdot$ & . & . & . & . \\
\hline & ecu & . & . & . & . & . & . & . & . & . & . & . & . & . \\
\hline & goe & . & . & . & . & . & . & . & . & . & . & . & . & . \\
\hline & $o b t$ & . & . & . & . & . & . & 1 & . & . & . & . & . & . \\
\hline & ven & . & . & . & . & . & . & . & . & . & . & . & . & . \\
\hline \multirow{5}{*}{ Hc31 } & cle & . & . & . & . & $\cdot$ & . & $\cdot$ & . & . & . & . & . & . \\
\hline & ecu & . & . & . & . & . & . & . & . & . & . & . & . & . \\
\hline & goe & . & . & . & . & . & . & . & . & . & . & . & . & . \\
\hline & $o b t$ & . & . & . & . & . & . & 2 & . & . & . & . & . & . \\
\hline & ven & . & . & . & . & . &. & . & . & . & . & . & . & . \\
\hline \multirow{5}{*}{ Hc32 } & cle & . & . & . & . & . & . & . & $\cdot$ & $\cdot$ & . & . & . & . \\
\hline & $e c u$ & . & . & . & . & . & . & . & . & . & . & . & . & . \\
\hline & goe & . & . & . & . & . & . & . & . & . & . & . & . & . \\
\hline & $o b t$ & . & . & . & . & 2 & . & . & . & . & . & . & . & . \\
\hline & ven & . & . & . & . & . & . & . & . & . & . & . & . & . \\
\hline \multirow{5}{*}{ Hc33 } & cle & . & $\cdot$ & . & . & $\cdot$ & $\cdot$ & $\cdot$ & $\cdot$ & $\cdot$ & . & . & $\cdot$ & . \\
\hline & ecu & . & . & . & . & . & . & . & . & . & . & . & . & . \\
\hline & goe & . & . & . & . & . & . & . & . & . & . & . & . & . \\
\hline & $o b t$ & . & . & . & . & . & . & . & . & . & . & . & 3 & . \\
\hline & ven & . & . & . & . & . & . & . & . & . & . & . & . & . \\
\hline \multirow{5}{*}{ Hc34 } & cle & . & . & . & . & . & . & . & . & $\cdot$ & . & . & . & . \\
\hline & ecu & . & . & . & . & $\cdot$ & $\cdot$ & $\cdot$ & . & . & . & . & . & . \\
\hline & goe & . & . & . & . & . & . & . & . & . & . & . & . & . \\
\hline & $o b t$ & . & . & . & . & . & . & $\cdot$ & $\cdot$ & . & . & 1 & . & . \\
\hline & ven & . & . & . & . & . & . & . & . & . & . & . & . & . \\
\hline
\end{tabular}




\begin{tabular}{|c|c|c|c|c|c|c|c|c|c|c|c|c|c|c|}
\hline \multirow{5}{*}{ Hc35 } & cle & . & . & . & . & . & . & . & . & . & . & . & . & . \\
\hline & ecu & . & . & . & . & . & . & . & . & . & . & . & . & . \\
\hline & goe & . & . & . & . & . & . & . & . & . & . & . & . & . \\
\hline & $o b t$ & . & . & . & . & . & . & . & . & . & . & . & 1 & . \\
\hline & ven & . &. & . & . & . & . &. & . & . & . & . & . & . \\
\hline \multirow{5}{*}{ Hc36 } & cle & . & . & . & . & . & . & . & $\cdot$ & . & . & . & . & . \\
\hline & ecu & . & . & . & . & . & . & . & . & . & . & . & . & . \\
\hline & goe & . & . & . & . & . & . & . & . & . & . & . & . & . \\
\hline & $o b t$ & . & . & . & . & . & . & . & . & . & . & . & . & . \\
\hline & ven & . & . & . & . & . & 1 & . & . & . & . & . & . & . \\
\hline \multirow{5}{*}{ Hc37 } & cle & . & . & . & . & . & . & . & $\cdot$ & $\cdot$ & . & . & $\cdot$ & . \\
\hline & ecu & . & . & . & . & . & . & . & . & . & . & . & . & . \\
\hline & goe & . & . & . & . & . & . & . & . & . & . & . & . & . \\
\hline & $o b t$ & . & . & . & . & . & . & . & . & . & . & . & . & . \\
\hline & ven & . & . & . & . & . & . & 1 & 1 & . & . & . & . & . \\
\hline \multirow{5}{*}{ Hc38 } & cle & . & . & . & . & . & . & . & $\cdot$ & $\cdot$ & . & . & $\cdot$ & . \\
\hline & ecu & . & . & . & . & . & . & . & . & . & . & . & . & . \\
\hline & goe & . & . & . & . & . & . & . & . & . & . & . & . & . \\
\hline & $o b t$ & . & . & . & $\cdot$ & . & . & . & . & . & . & . & $\cdot$ & . \\
\hline & ven & . &. & . & . & . & . & 2 & . & . & . & . & . & . \\
\hline \multirow{5}{*}{ Hc39 } & cle & . & . & . & . & . & . & . & $\cdot$ & $\cdot$ & . & . & . & . \\
\hline & ecu & . & . & . & . & . & . & . & . & . & . & . & . & . \\
\hline & goe & . & . & . & . & . & . & . & . & . & . & . & . & . \\
\hline & $o b t$ & . & . & . & . & . & . & . & . & . & . & . & . & . \\
\hline & ven & . & . & . & . & . & . & . & 3 & . & . & . & . & . \\
\hline \multirow{5}{*}{ Hc40 } & cle & . & . & $\cdot$ & . & . & . & . & $\cdot$ & . & . & . & . & . \\
\hline & ecu & . & . & . & . & . & . & . & . & . & . & . & . & . \\
\hline & goe & . & . & . & . & . & . & . & . & . & . & . & $\cdot$ & . \\
\hline & $o b t$ & . & . & . & . & . & . & $\cdot$ & . & . & . & . & . & . \\
\hline & ven & . & . & . & . & . & . & . & 1 & . & . & . & . & . \\
\hline
\end{tabular}


Supplementary Table 6. Spatial analysis of molecular variance (SAMOVA) results for ITS and cpDNA (trnL-F, trnH-psbA and rp/32-trnL) showing the variance amongst groups ( $\mathrm{F}_{\mathrm{CT}}$ values) for pre-defined $\mathrm{K}$ number of groups.

\begin{tabular}{|c|c|c|c|c|c|c|c|c|c|c|c|c|}
\hline & $\mathrm{K}$ & & & & & & & & & & & \\
\hline & 2 & 3 & 4 & 5 & 6 & 7 & 8 & 9 & 10 & 11 & 12 & 13 \\
\hline$F_{\text {CT ITS }}$ & 0.595 & 0.622 & 0.608 & 0.608 & 0.603 & 0.581 & 0.505 & 0.507 & 0.468 & 0.481 & 0.504 & 0.639 \\
\hline$F_{c T} \mathrm{cpDNA}$ & 0.417 & 0.426 & 0.417 & 0.414 & 0.412 & 0.406 & 0.405 & 0.410 & 0.441 & 0.502 & 0.675 & - \\
\hline
\end{tabular}


Supplementary Table 7. Pairwise Fst values amongst clusters calculated from ITS and cpDNA (trnL-F, trnH-psbA and $r p / 32-t r n L)$. Results for ITS are shown below the diagonal and cpDNA above. Bold numbers indicate significance at the $5 \%$ level.

\begin{tabular}{|c|c|c|c|c|c|c|c|c|c|c|c|c|c|c|}
\hline & A & B & C & D & $E$ & $F$ & $\mathrm{G}$ & $\mathrm{H}$ & I & $\mathrm{J}$ & $\mathrm{K}$ & L & M & $\mathrm{N}$ \\
\hline$A$ & & - & - & - & - & - & - & - & - & - & - & - & - & - \\
\hline$B$ & - & & 0.134 & 0.112 & 0.136 & 0.001 & 0.504 & 0.101 & 0.211 & 0.586 & - & 0.462 & 0.713 & - \\
\hline C & - & 0.092 & & 0.028 & 0.050 & 0.038 & 0.206 & -0.003 & 0.157 & 0.200 & - & 0.417 & 0.690 & - \\
\hline$D$ & - & 0.141 & 0.050 & & 0.023 & 0.166 & 0.530 & 0.220 & 0.264 & 0.597 & - & 0.470 & 0.740 & - \\
\hline$E$ & - & 0.290 & -0.073 & 0.200 & & 0.048 & 0.511 & 0.113 & 0.076 & 0.712 & - & 0.414 & 0.874 & - \\
\hline$F$ & - & 0.147 & 0.106 & 0.201 & 0.101 & & 0.342 & 0.000 & 0.109 & 0.402 & - & 0.408 & 0.621 & - \\
\hline $\mathrm{G}$ & - & 0.267 & 0.061 & 0.249 & 0.206 & 0.089 & & 0.188 & 0.452 & -0.080 & - & 0.646 & 0.794 & - \\
\hline $\mathrm{H}$ & - & 0.258 & 0.120 & 0.258 & 0.028 & 0.051 & 0.052 & & 0.095 & 0.207 & - & 0.406 & 0.581 & - \\
\hline I & - & 0.232 & 0.055 & 0.202 & -0.046 & 0.141 & 0.127 & 0.087 & & 0.532 & - & 0.444 & 0.724 & - \\
\hline J & - & 0.498 & 0.065 & 0.484 & 0.485 & 0.406 & 0.232 & 0.276 & 0.122 & & - & 0.698 & 0.989 & - \\
\hline $\mathrm{K}$ & - & - & - & - & - & - & - & - & - & - & & - & - & - \\
\hline $\mathrm{L}$ & - & 0.629 & 0.474 & 0.635 & 0.482 & 0.659 & 0.660 & 0.661 & 0.537 & 0.595 & - & & 0.657 & - \\
\hline M & - & 0.702 & 0.531 & 0.708 & 0.601 & 0.715 & 0.718 & 0.704 & 0.563 & 0.688 & - & 0.296 & & - \\
\hline$N$ & - & - & - & - & - & - & - & - & - & - & - & - & - & \\
\hline & $A$ & B & C & D & $E$ & $\mathrm{~F}$ & G & $\mathrm{H}$ & I & $\mathrm{J}$ & $\mathrm{K}$ & $\mathrm{L}$ & $\mathrm{M}$ & $\mathrm{N}$ \\
\hline
\end{tabular}


Supplementary Table 8. Molecular diversity indices for ITS and cpDNA (trnL-F, trnH-psbA and $r p / 32-t r n L)$ for each cluster. Clusters $(A-N)$ as described in Figure 1 and

Supplementary Table 1. Metrics were not applicable (n.a.) for clusters with less than three individuals. N, number of individuals; h, haplotype diversity ( \pm SD); $\pi$, nucleotide diversity ( \pm $\mathrm{SD})$.

\begin{tabular}{|c|c|c|c|c|c|c|c|c|}
\hline & \multicolumn{4}{|l|}{ ITS } & \multicolumn{4}{|l|}{ cpDNA } \\
\hline & $\begin{array}{l}\text { SAMOVA } \\
\text { group }\end{array}$ & $\mathrm{N}$ & $\mathrm{h}$ & $\pi \times 100$ & $\begin{array}{l}\text { SAMOVA } \\
\text { group }\end{array}$ & $\mathrm{N}$ & $\mathrm{h}$ & $\pi \times 100$ \\
\hline A & 1 & 2 & n.a. & n.a. & - & - & - & - \\
\hline B & 1 & 13 & $0.69 \pm 0.12$ & $0.76 \pm 0.46$ & 1 & 10 & $0.82 \pm 0.10$ & $2.34 \pm 1.25$ \\
\hline C & 1 & 10 & $0.82 \pm 0.10$ & $2.95 \pm 1.63$ & 1 & 5 & $0.90 \pm 0.16$ & $3.95 \pm 2.41$ \\
\hline D & 1 & 14 & $0.85 \pm 0.07$ & $0.63 \pm 0.39$ & 1 & 6 & $0.73 \pm 0.16$ & $2.78 \pm 1.62$ \\
\hline $\mathrm{E}$ & 1 & 3 & $0.67 \pm 0.31$ & $0.72 \pm 0.63$ & 1 & 3 & $1.00 \pm 0.27$ & $2.15 \pm 1.62$ \\
\hline $\mathrm{F}$ & 1 & 24 & $0.86 \pm 0.04$ & $0.67 \pm 0.40$ & I & 17 & $0.93 \pm 0.04$ & $2.68 \pm 1.36$ \\
\hline G & I & 23 & $0.76 \pm 0.08$ & $0.66 \pm 0.40$ & 1 & 20 & $0.77 \pm 0.08$ & $1.69 \pm 0.86$ \\
\hline $\mathrm{H}$ & 1 & 34 & $0.83 \pm 0.03$ & $0.84 \pm 0.48$ & 1 & 25 & $0.92 \pm 0.03$ & $3.10 \pm 1.55$ \\
\hline I & I & 34 & $0.67 \pm 0.05$ & $1.88 \pm 0.98$ & 1 & 10 & $0.91 \pm 0.08$ & $2.20 \pm 1.18$ \\
\hline $\mathrm{J}$ & 1 & 7 & $0.91 \pm 0.10$ & $0.56 \pm 0.39$ & 1 & 3 & $0.67 \pm 0.31$ & $0.09 \pm 0.08$ \\
\hline $\mathrm{K}$ & $\|$ & 1 & n.a. & n.a. & 1 & 1 & n.a. & n.a. \\
\hline $\mathrm{L}$ & ॥ & 15 & $0.55 \pm 0.14$ & $2.36 \pm 1.27$ & II & 8 & $0.64 \pm 0.18$ & $2.13 \pm 1.18$ \\
\hline M & III & 16 & $0.13 \pm 0.11$ & $1.46 \pm 0.80$ & III & 9 & $0.75 \pm 0.11$ & $0.06 \pm 0.05$ \\
\hline $\mathrm{N}$ & ॥ & 1 & n.a. & n.a. & II & 1 & n.a. & n.a. \\
\hline
\end{tabular}


795 Supplementary Fig. 1 MST and distribution of ITS haplotypes. Numbers refer to 796 haplotypes listed in Supplementary Table 5. Haplotypes are coloured according to 797 species. Shared haplotypes are shown in white. Detail of species sharing haplotypes 798 is given in Fig. 3. Hypothetical haplotypes are represented by filled black circles. 799 Letters on the map refer to clusters as described in Figure 1 and Supplementary 800 Table 3. Pie charts are proportional to sample size for each cluster $(\mathrm{N}=1-34)$.

801 Numbers next to each segment refer to haplotype number. NA: northern Andes, SA: 802 southern Andes

803 Supplementary Fig. 2 MST and distribution of cpDNA (trnL-F, trnH-psbA and 804 rpl32-trnL) haplotypes. Numbers refer to haplotypes listed in Supplementary Table 805 6. Haplotypes are coloured according to species. Shared haplotypes are shown in 806 white. Detail of species sharing haplotypes is given in Fig. 5. Hypothetical 807 haplotypes are represented by filled black circles, numbers within indicate their 808 number when more than one. Letters on the map refer to clusters as described in 809 Figure 1 and Supplementary Table 3. Pie charts are proportional to sample size for 810 each cluster $(\mathrm{N}=1-25)$. Numbers next to each segment refer to haplotype number. 811 NA: northern Andes, SA: southern Andes

812 Supplementary Fig. 3 NeighborNet network showing genetic relatedness amongst 813 the South American species of Oreobolus based on ITS FST pairwise values 814 considering (a) O. obtusangulus as one species (b) O. obtusangulus as two species

815 Supplementary Fig. 4 NeighborNet network showing genetic relatedness amongst 816 the South American species of Oreobolus based on cpDNA ( $\operatorname{trn} \mathrm{L}-\mathrm{F}$, $\operatorname{trn} \mathrm{H}-p s b \mathrm{~A}$ and 
817 rpl32-trnL) FST pairwise values considering (a) O. obtusangulus as one species (b)

818 O. obtusangulus as two species 


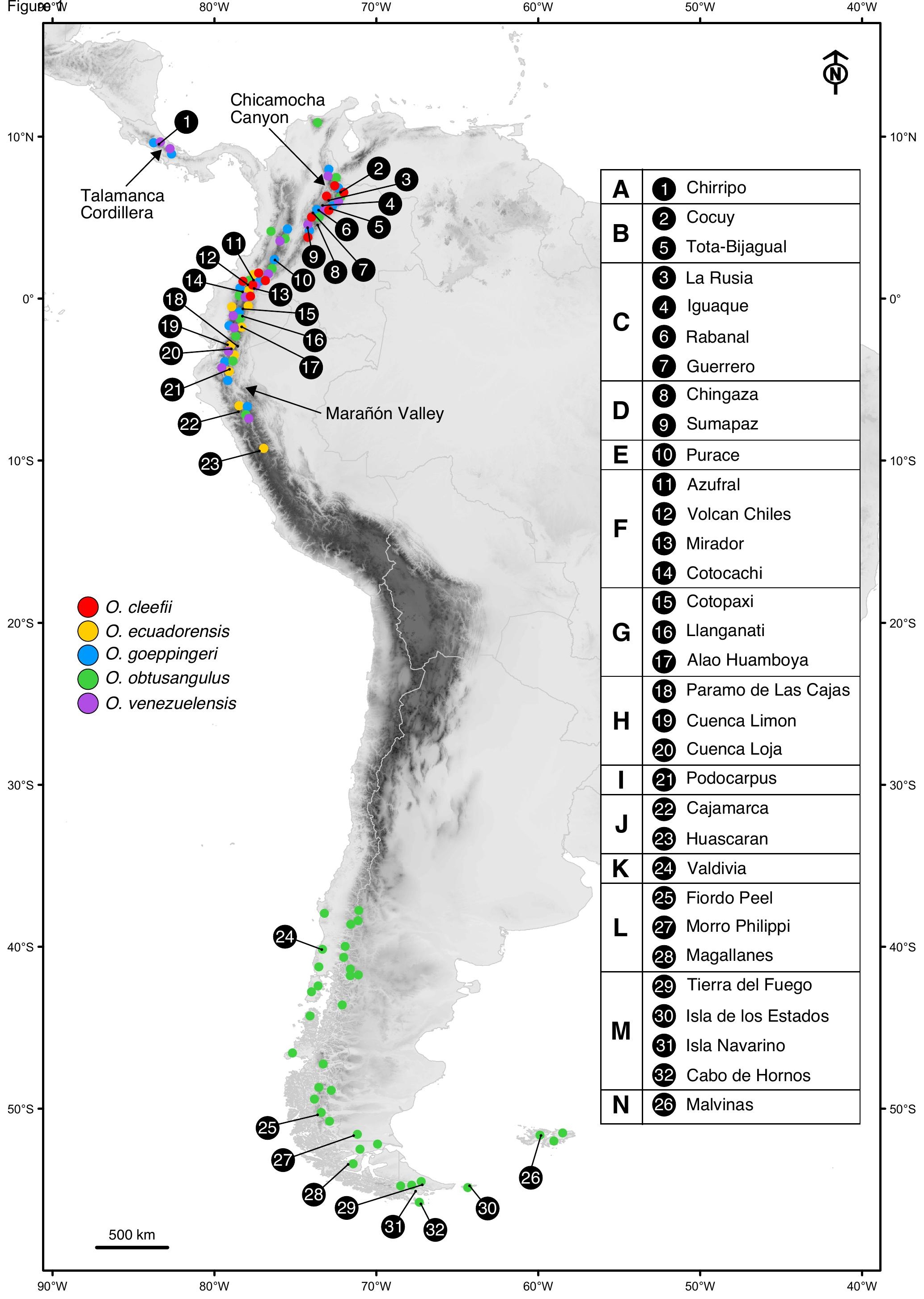


Figure 2

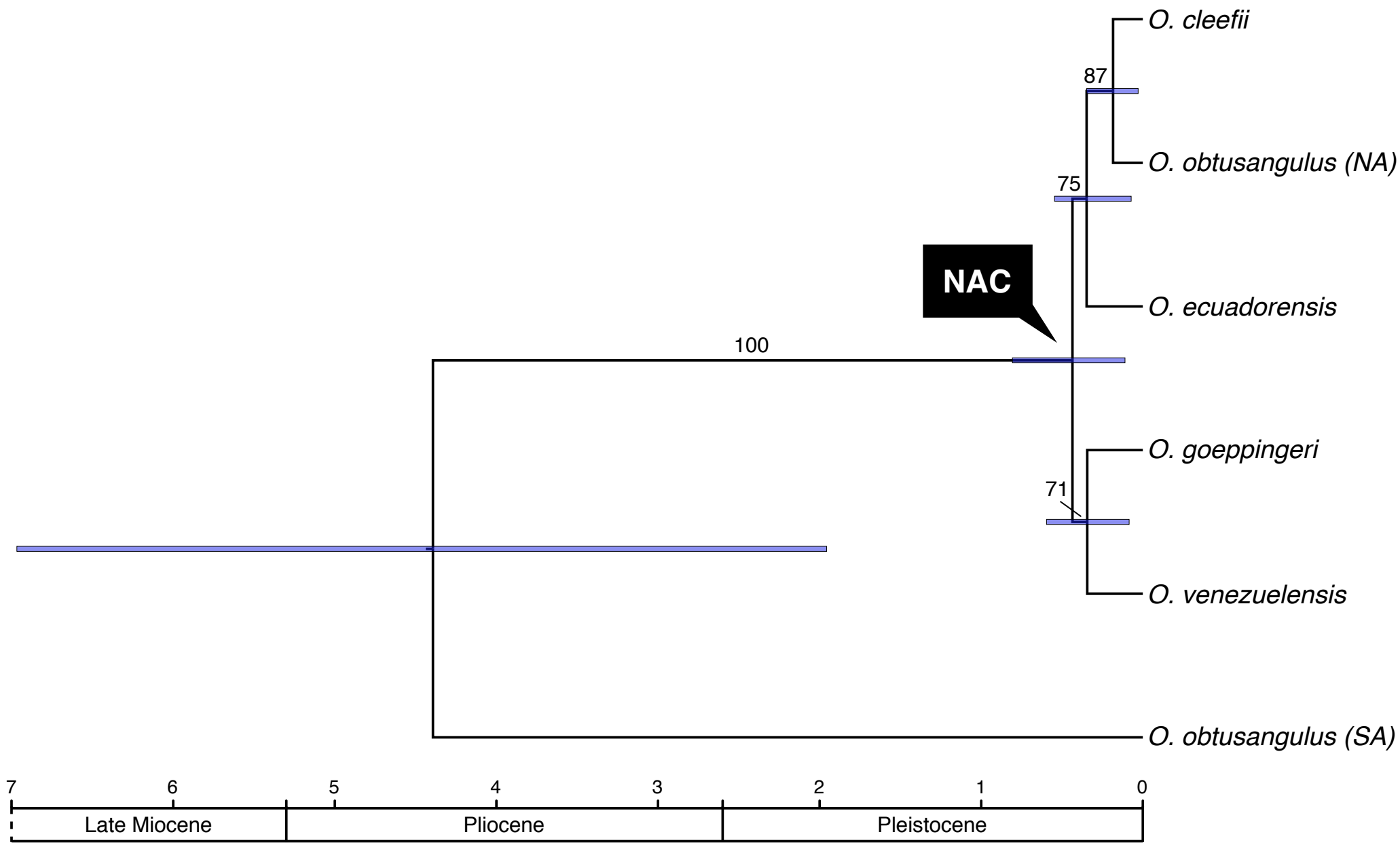




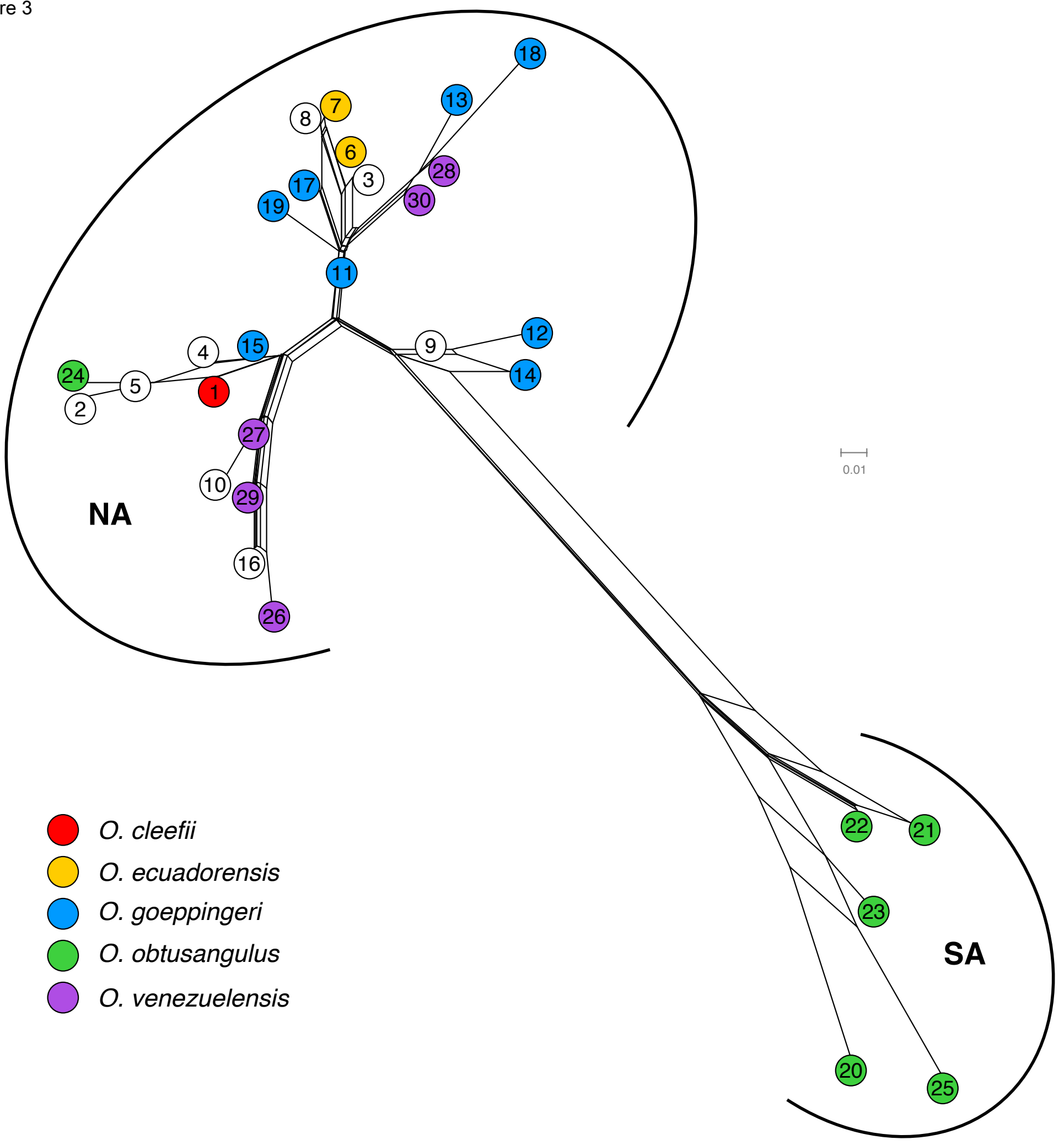

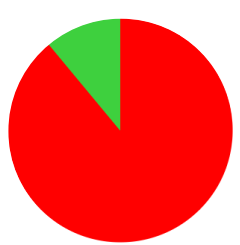

2

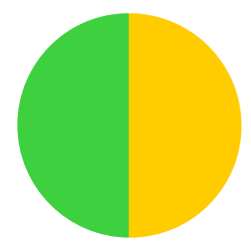

8

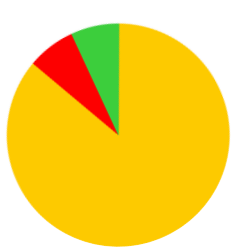

3

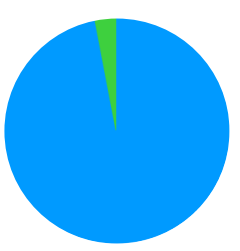

9

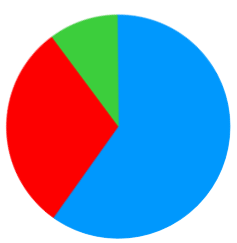

4

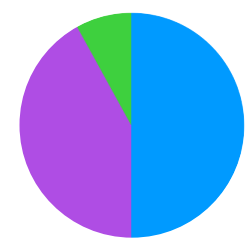

10

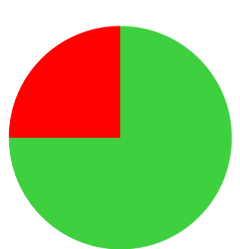

5

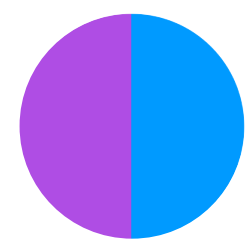

16 


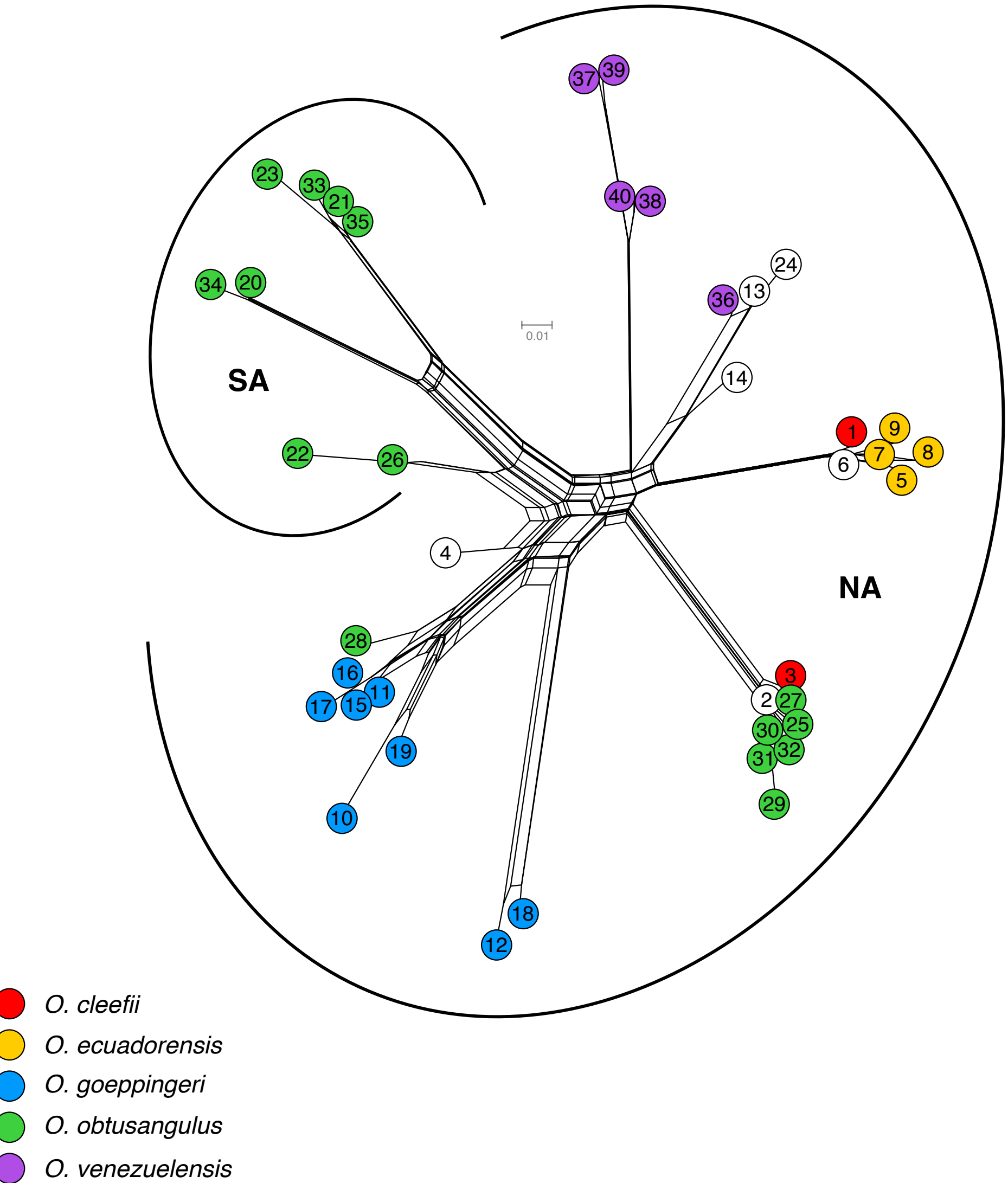

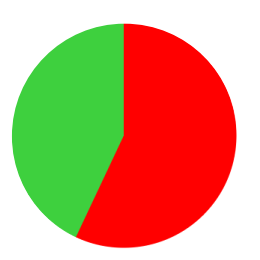

2

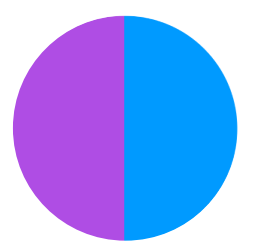

13
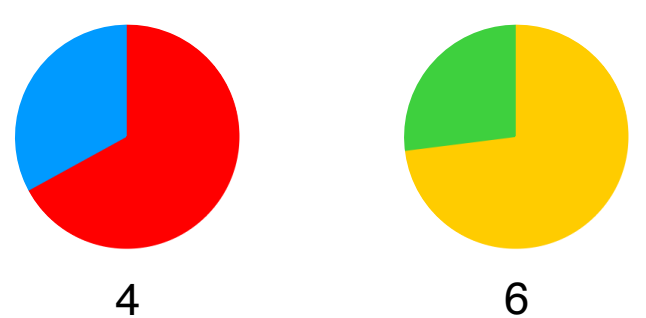

6

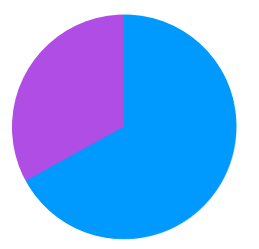

14

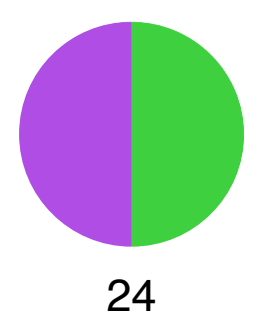


Figure 5

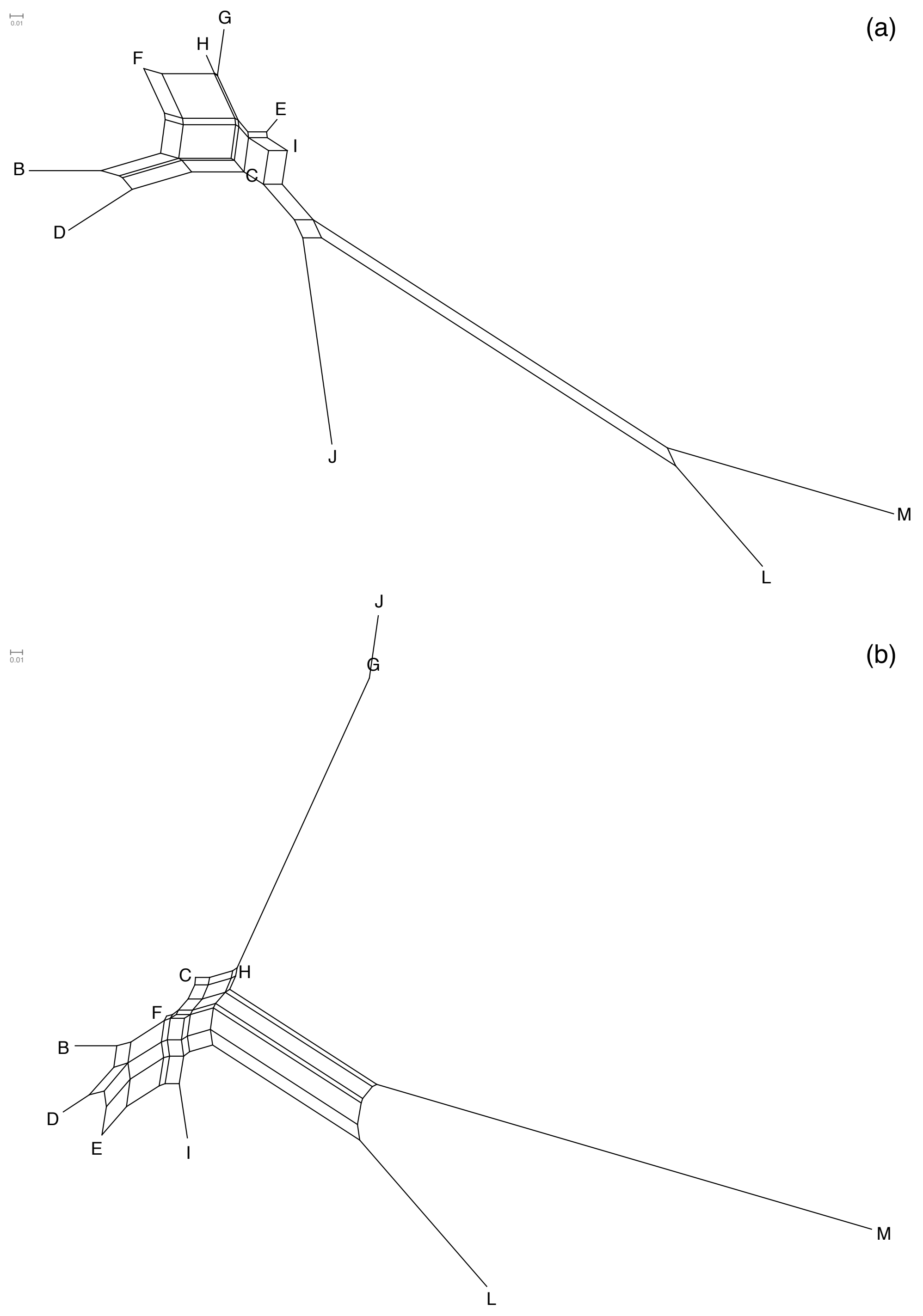


Click here to access/download Supplementary Material

Gomez-Gutierrez et al Supplementary Figure 1.pdf 
Click here to access/download Supplementary Material

Gomez-Gutierrez et al Supplementary Figure 2.pdf 
Click here to access/download Supplementary Material

Gomez-Gutierrez et al Supplementary Figure 3.pdf 
Click here to access/download Supplementary Material

Gomez-Gutierrez et al Supplementary Figure 4.pdf 